\title{
The renal cortical interstitium: morphological and functional aspects
}

\author{
Brigitte Kaissling $•$ Michel Le Hir
}

Accepted: 27 May 2008 / Published online: 25 June 2008

(C) Springer-Verlag 2008

\begin{abstract}
The renal interstitial compartment, situated between basement membranes of epithelia and vessels, contains two contiguous cellular networks. One network is formed by interstitial fibroblasts, the second one by dendritic cells. Both are in intimate contact with each other. Fibroblasts are interconnected by junctions and connected to basement membranes of vessels and tubules by focal adhesions. Fibroblasts constitute the "skeleton" of the kidney. In the renal cortex, fibroblasts produce erythropoietin and are distinguished from other interstitial cells by their prominent F-actin cytoskeleton, abundance of rough endoplasmic reticulum, and by ecto-5'-nucleotidase expression in their plasma membrane. The resident dendritic cells belong to the mononuclear phagocyte system and fulfil a sentinel function. They are characterized by their expression of MHC class II and CD11c. The central situation of fibroblasts suggests that signals from tubules, vessels, and inflammatory cells converge in fibroblasts and elicit an integrated response. Following tubular damage and inflammatory signals fibroblasts proliferate, change to the myofibroblast phenotype and increase their collagen production, potentially resulting in renal fibrosis. The acquisition of a profibrotic phenotype by fibroblasts in renal diseases is generally considered a main causal event in the progression of chronic renal failure. However, it might also be seen as a repair process.
\end{abstract}

Keywords Myofiboblasts $\cdot$ Dendritic cells $\cdot$ Unilateral ureter obstruction · Thiazide diuretics · Morphology

B. Kaissling $(\bowtie) \cdot$ M. Le Hir

Institute of Anatomy, Division Vegetative Anatomy,

University of Zürich, Winterthurerstr. 190,

8057 Zurich, Switzerland

e-mail: brigitte.kaissling@access.uzh.ch

M. Le Hir

e-mail: lehir@anatom.uzh.ch

\section{Introduction}

In all parenchymal organs, including the kidney, the interstitium is situated in the space between the basement membranes of the epithelial cells and of the nutritive capillaries (Fig. 1). This compartment is of eminent functional relevance in the healthy and diseased kidney.

The fibroblasts in the interstitium provide the "skeleton" of the tissue and maintain the three-dimensional architecture of the tissue. The interstitium is necessarily involved in all intrarenal exchange processes since the reabsorption and secretion of fluid and solutes implicates a transit across the interstitial compartment. Cortical fibroblasts play a role in the production of regulatory substances, such as extracellular adenosine (Le Hir and Kaissling 1993) and erythropoietin (Bachmann et al. 1993; Maxwell et al. 1993). In the healthy organ dendritic cells, belonging to the mononuclear phagocyte system, reside in the interstitium in line with their sentinel function. In disease, various inflammatory cells infiltrate the interstitium. In the diseased kidney, the cellular content as well as the content of fibers and matrix in the interstitium increases, eventually yielding renal fibrosis.

The cortical interstitium, and in particular the fibroblasts, are often overlooked in conventional tissue preparations of healthy kidneys. However, under inflammatory conditions the interstitial space becomes massively expanded and fibroblasts acquire the myofibroblast phenotype: they express alpha smooth muscle actin ( $\alpha$ SMA) and have an increased capacity for production of collagen fibrils and matrix.

In this review based on studies in rats and mice we describe the morphology of interstitial cells of the healthy renal cortex and in various models of diseases. The observations suggest that fibroblasts are the pivotal cells in the renal interstitium. 


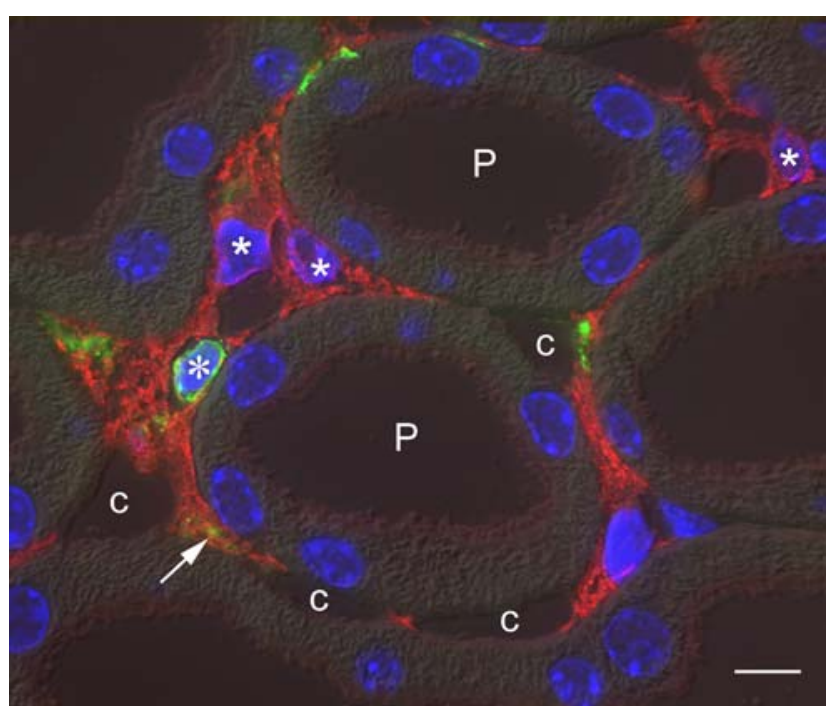

Fig. 1 Cortical peritubular interstitium in a mouse kidney ( $3 \mu \mathrm{m}$ cryostat section). The interstitial space extends between tubules and capillaries $(c)$. It is occupied by fibroblasts (stars) and their processes, expressing 5'NT (red) and dendritic cells (asterisks), expressing MHC class II (green). Cellular nuclei are labeled in blue; the tissue structure is shown by differential interference contrat (DIC). The brush border of proximal tubules $(P)$ is weakly labeled by $5^{\prime}$ NT. Bar $10 \mu \mathrm{m}$

\section{Problems in studying interstitial cells in the kidney}

Following older electron microscopic investigations (Bulger and Nagle 1973; Lemley and Kriz 1991; TakahashiIwanaga 1991) only a few reports dealt with the structure of interstitial cells in healthy kidney. The reasons are mostly technical. The study of the cells in the cortical interstitium is difficult since after immersion fixation the interstitial space and the capillaries are usually collapsed whereas tubules are swollen. The light microscopic distinction between fibroblasts, endothelial cells, and dendritic cells is awkward in such tissue preparations. Only perfusion fixation and the use of thin light microscopic $(<3 \mu \mathrm{m})$ sections and of electron microscopy provide a reasonably safe distinction of fibroblasts and other interstitial cells.

\section{Identification of cortical fibroblasts by immunostainings}

The study of renal fibroblasts is further hampered by the lack of marker proteins expressed in all fibroblasts in all functional stages and exclusively in fibroblasts.

Nevertheless, a couple of proteins have been proposed to identify fibroblasts in healthy and diseased kidneys, the most propagated one being the "fibroblast specific protein 1 (FSP1) (Strutz et al. 1995) which corresponds to the small cytoplasmic calcium-binding protein S100A4 and plays a role in cell motility (Garrett et al. 2006, 2008). In the healthy kidney only very few cells in the interstitial space are recognized by antibodies against S100A4/FSP1. This number is by far too small to comprehend the entire population of fibroblasts in the healthy kidney. In the diseased kidney, the incidence of S100A4/FSP1-positive cells increases in parallel with the amount of infiltrating leukocytes (Inoue et al. 2005). In fact, in the healthy as well as in the diseased kidney S100A4/FSP1 co-localizes with leukocyte markers (Inoue et al. 2005; Le Hir et al. 2005; Rossini et al. 2005). S100A4/FSP1 also labels smooth muscle cells of arterioles (Le Hir et al. 2005) and metastasing cells (Davies et al. 1993; Gibbs et al. 1994; Mazzucchelli 2002; Garrett et al. 2006). Recently the stromal cadherin 9 (Thedieck et al. 2007) has been proposed as surface marker for fibroblasts in the human kidney. Cadherin 9 is expressed in a very small population of interstitial cells in healthy kidneys. In the diseased kidney the incidence of labeled cells is higher. Cadherin 9 partially co-localizes with cells labeled by FSP1/S100A4 and with mononuclear cells (Thedieck et al. 2007).

Alpha SMA is expressed in fibroblasts of the adult kidney only under pathological conditions. In other words $\alpha$ SMA allows the identification myofibroblasts but not of the fibroblasts of the healthy kidney.

Other proteins that label interstitial fibroblasts are the soluble guanylyl cyclase (sGC) (Theilig et al. 2001) and the membrane-bound ecto-5'-nucleotidase (5'NT) (Dawson et al. 1989; Le Hir et al. 1989; Gandhi et al. 1990). Both proteins recognize interstitial cells (Ito cells) in the liver as well (Schmid et al. 1994; Theilig et al. 2001) and are functionally related with regulation of hemodynamic parameters (Le Hir and Kaissling 1993). In the renal cortex, in addition to peritubular fibroblasts, mesangial cells, and perivascular cells express sGC. The enzyme 5'NT is identical with CD73 (Thompson et al. 1989). In the interstitial space it is strongly expressed in the plasma membrane of cortical peritubular fibroblasts, and weakly in a small subgroup of T-lymphocytes. Furthermore, it is expressed in the brush border membrane of proximal tubular cells and in the apical or basolateral plasma membrane of intercalated cells. In mice ${ }^{\prime}$ NT also labels mesangial cells (Le Hir and Kaissling 1993). The epithelial and mesangial locations of $5^{\prime} \mathrm{NT}$ do not impair its usefulness as marker for cortical fibroblasts within the interstitium. The occasionally CD73-positive lymphocytes can hardly been mistaken as fibroblasts due to their small size and their rounded shapes. Thus, $5^{\prime} \mathrm{NT}$ is a reliable marker for identification of renal cortical fibroblasts (Figs. 1, 2). The identification of fibroblasts as source of renal erythropoietin was possible due to the distinct outlining of interstitial fibroblasts by $5^{\prime} \mathrm{NT}$ (Bachmann et al. 1993; Maxwell et al. 1993, 1997). In a 5'NT-expressing cell line derived from adult renal fibroblasts hypoxic or 
Fig. 2 Interstitial cells, highlighted by immunogold staining for ecto-5'-nucleotidase (a) and MHC class II (b) on consecutive cryostat sections. a 5'NT, detected by immunogold, depicts the abundance of interstitial fibroblasts (arrow); the brush border of proximal tubules $(P)$ is stained too. b Immunogold labeling for MHC class II reveals the distribution of dendritic cells (arrow) throughout the interstitium. Bar $50 \mu \mathrm{m}$

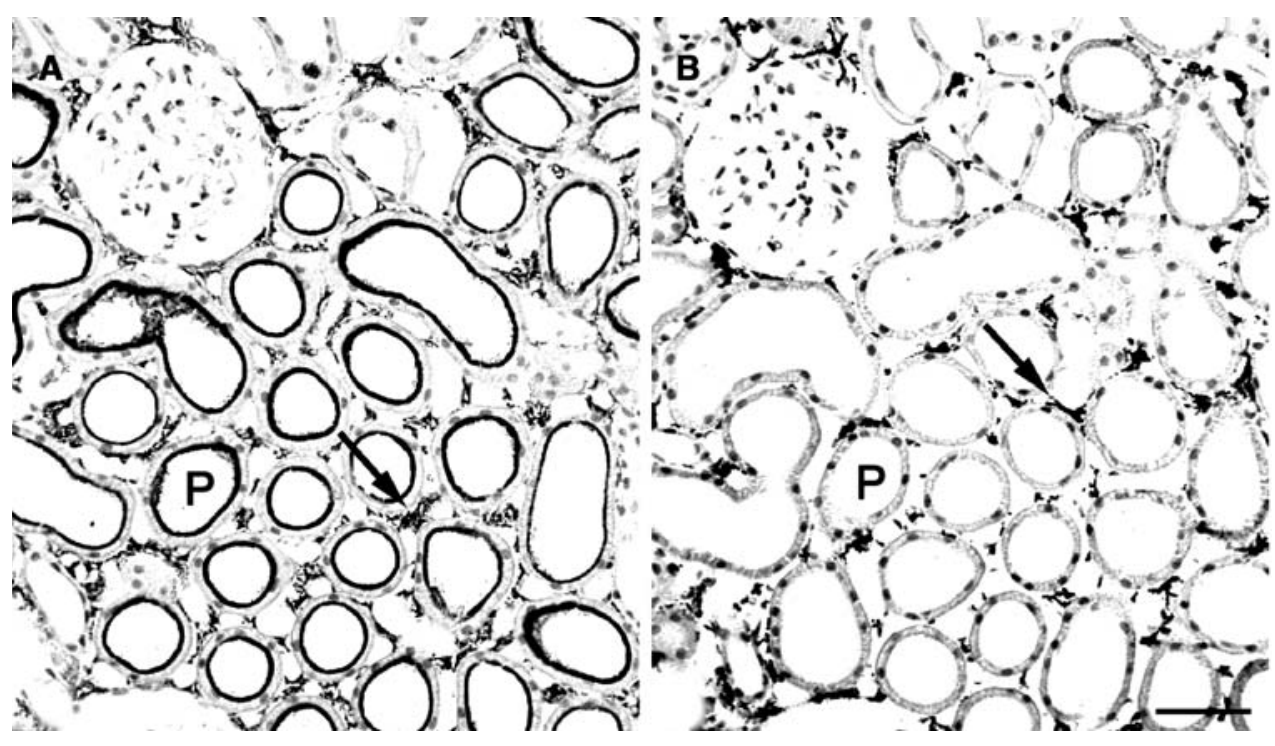

anoxic incubation conditions provoked erythropoietin expression and increased vascular endothelial growth factor expression (Plotkin and Goligorsky 2006).

In contrast with cortical interstitial fibroblasts, fibroblasts of the renal capsule, of the periarterial connective tissue sheath, and of the medulla do not or only weakly express $5^{\prime} \mathrm{NT}$.

\section{Developmental aspects of cortical peritubular fibroblasts}

The sharing by renal fibroblasts of many proteins ascribed typically to either mesenchymal cells or to epithelial cells might be rooted in the developmental origin of renal fibroblasts. Unlike in other epithelial organs, where epithelial and stromal cells arise from different blastema, the metanephric mesenchyme gives rise to both, epithelia and stroma. Whereas the signaling cascades promoting the transformation of metanephric mesenchymal cells to epithelial cells are extensively studied, little is known about the differentiation of the mesenchymal cells to interstitial fibroblasts (Ekblom and Weller 1991; Alcorn et al. 1999). During embryogenesis part of the metanephric mesenchyme is induced to develop into nephron epithelia. These prospective epithelial cells are surrounded by a population of supporting mesenchymal cells, which express the winged helix transcription factor BF-2. BF-2 seems to determine the fate of this population of mesenchymal cells to maintain the mesenchymal phenotype and to differentiate later to cortical fibroblasts (Hatini et al. 1996). The expression of $\alpha \mathrm{SMA}$ apparently depends on signaling by Wnt-4, a member of the Wnt family of secreted signaling molecules. Wnt-4 probably performs this function in the developing kidney by activating the Bmp- 4 gene encoding a known differentiation factor for $\alpha$ SMA (Itaranta et al. 2006).

In newborn rats the stromal cells in the kidney display $\alpha$ SMA, vimentin (Marxer-Meier et al. 1998), and nestin, which is associated with vimentin (Sakairi et al. 2007). Yet, they are all negative for $5^{\prime} \mathrm{NT}$, although at that time point the enzyme is well detectable in its epithelial locations. In the latter the "mesenchymal" cytoskelettal proteins $(\alpha$ SMA and vimentin) are downregulated. The cortical peritubular fibroblasts (but not the medullary ones) loose $\alpha$ SMA- and vimentin as well as nestin expression gradually during the first two postnatal weeks, simultaneously with the gradual gain of $5^{\prime} \mathrm{NT}$. During a short period within the second postnatal week $\alpha$ SMA, vimentin, and 5'NT are co-expressed by the same cells. Three weeks after birth the peritubular cortical fibroblasts in healthy rat kidneys display the adult fibroblast phenotype, i.e. 5'NT in their plasma membrane, but neither vimentin, nor $\alpha \mathrm{SMA}$ in the cytoplasm (MarxerMeier et al. 1998). The fibroblasts in the juxtamedullary layer of the cortex, containing the most mature, oldest generation of nephrons, are the first to gain the "mature" stage. Interestingly, the fibroblasts in the periarterial interstitial tissue maintain during adult life a moderate $\alpha$ SMA- and vimentin expression associated with an extremely weak or undetectable 5'NT expression (Kaissling et al. 1996; Marxer-Meier et al. 1998). These observations strengthen the notion of the dependence of the fibroblast phenotype on the microenvironment.

\section{Cellular constituents of the healthy cortical interstitium}

Renal fibroblasts and dendritic cells (DC) (Figs. 1, 2) form closely enlaced networks in the interstitium. In healthy interstitium other cell types are found only occasionally. 
Morphology of fibroblasts

The fibroblasts in the peritubular interstitium (Figs. 2, 3) bridge the spaces between the capillaries and the epithelia (Kaissling and Le Hir 1994) and form a continuous network throughout the kidney. Renal fibroblasts display similar shapes and ultrastructure as fibroblasts in the interstitium of other organs (Sappino et al. 1990; Hashizume et al. 1992; Maxwell et al. 1997).

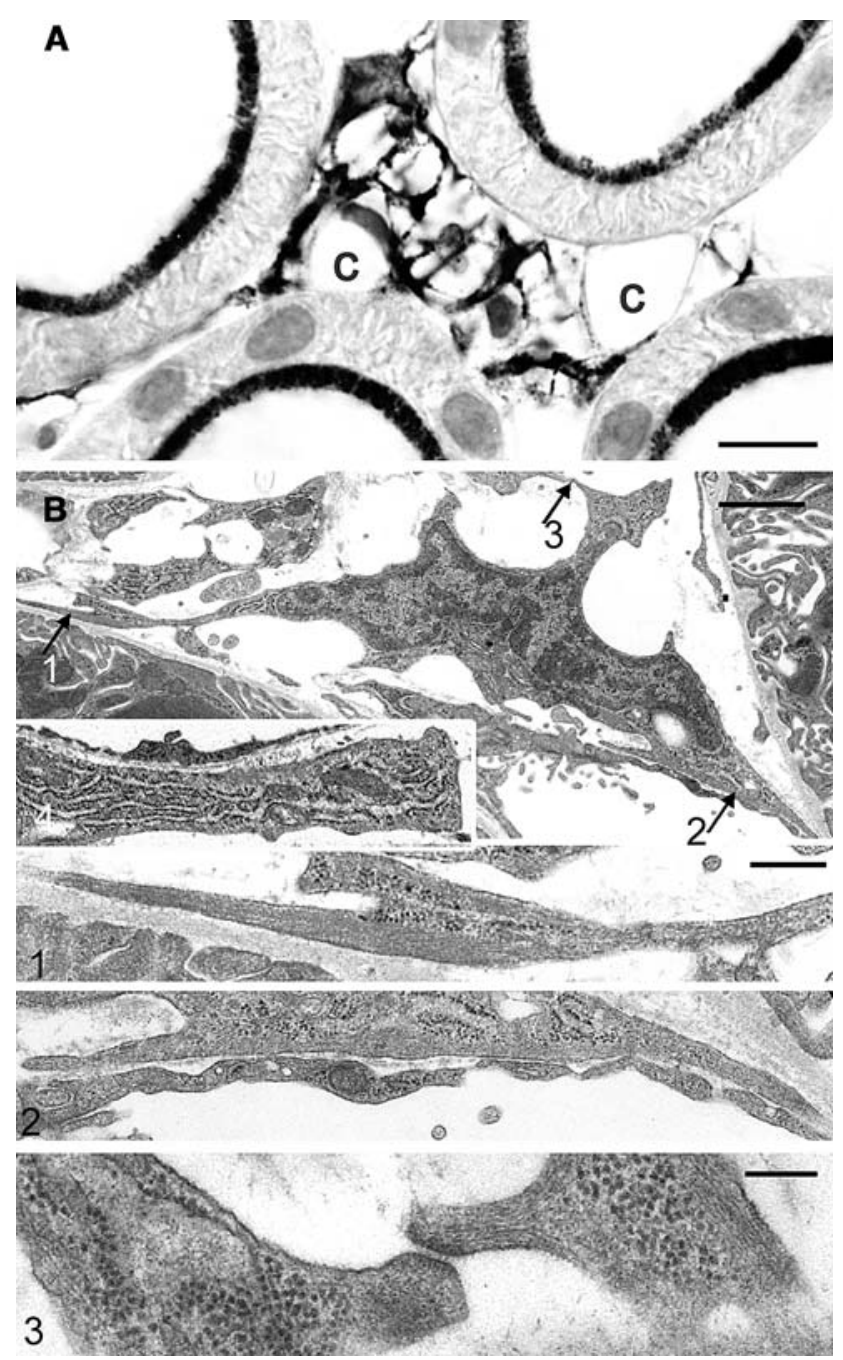

Fig. 3 Fibroblasts in the cortical peritubular interstitium. a Cryostat section. Fibroblasts, shown by immunogold labeling for 5'NT, bridge the interstitial space between the tubules and capillaries $(c)$; (b) transmission electron microscopy of healty rat kidney. Stellate pericaryon of a fibroblast, connected to the basement membrane of a proximal tubule ( 1 , magnified in insert 1$)$, the basement membrane of a capillary (2, magnified in insert 2) and to another fibroblast process (3, magnified in insert 3). Most cell organelles are located in cellular processes but lack in the pericaryon. Note the bundles of F-actin filaments at the connection sites. Insert 4 rough endoplasmic reticulum in a fibroblast process. Bars a $10 \mu \mathrm{m}, \mathbf{b} 1 \mu \mathrm{m}$, inserts $0.25 \mu \mathrm{m}$
Skeleton function

In healthy kidneys the pericaryon of the fibroblasts reveals a stellate profile with clear outlines (Figs.3, 4 and 5). Characteristic for cortical fibroblasts in healthy kidneys is the thin organelle-free cytoplasmic rim around the nucleus and the thin layer of actin filaments immediately under the plasma membrane, well apparent in transmission electron microscopy (Figs. 3, 5) and by staining for F-actin. The cellular processes are connected to the basement membranes by pedicle-like (rats) (Fig. 3) or spine-like (mouse) (Fig. 5) extensions. In these attachments the abundant F-actin filaments are suggestive of stress fibers. In addition to the contacts to basement membranes of capillaries and epithelia the fibroblast processes are also interconnected with each other by intermediate junctions (Fig. 3) (Lemley and Kriz 1991; Kaissling et al. 1996). By bracing the space between vessels, renal corpuscles, and loops of convoluted tubules the fibroblasts form a continuous network through the entire cortex thereby maintaining the tissue architecture.

The complex shape of fibroblasts in the kidney cortex is difficult to comprehend from two-dimensional images of tissue sections. Scanning electron microscopic images (Fig. 4) revealed that the larger fibroblast processes correspond to flat pierced leaves apposed to tubules and partly enveloping other structures, such as dendritic cells (Takahashi-Iwanaga 1991; Ina et al. 2002), whereas filiform processes span longer distances. The adhesions to the basement membranes of tubules and capillaries as well as to other fibroblasts suggest that cross-talk between epithelial cells and fibroblasts might be mediated not only by

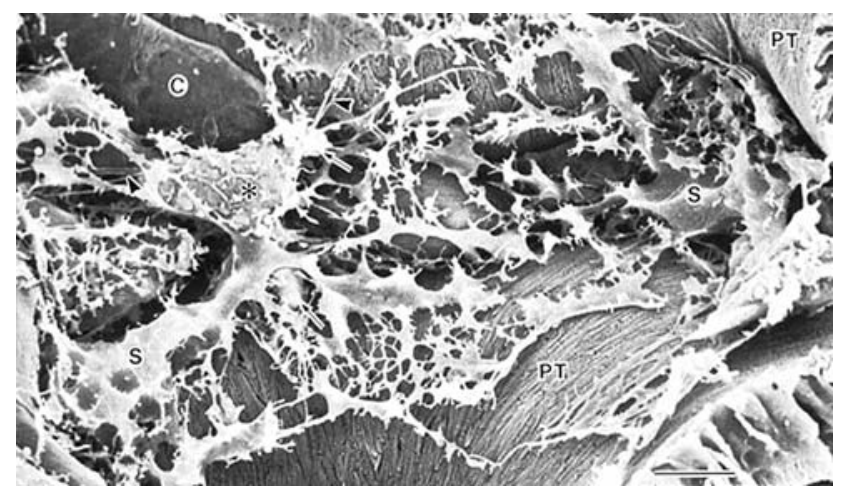

Fig. 4 Three-dimensional view of a fibroblast in the cortical interstitium of a rat. Scanning electron microscopy, after digestion of the tubular and vascular basement membranes The pericaryon $(S)$ shows characteristic sharp angles; the processes adjacent to the proximal tubule $(P T)$ are extremely attenuated and perforated; the asterisk indicates a dendritic cell enclosed by fibroblast processes, arrows and arrow heads indicate processes of the dendritic cell; $C$ capillary. Bar $10 \mu \mathrm{m}$. (Image from Takahashi-Iwanaga (1991) Cell Tissue Res 264:269-281) 


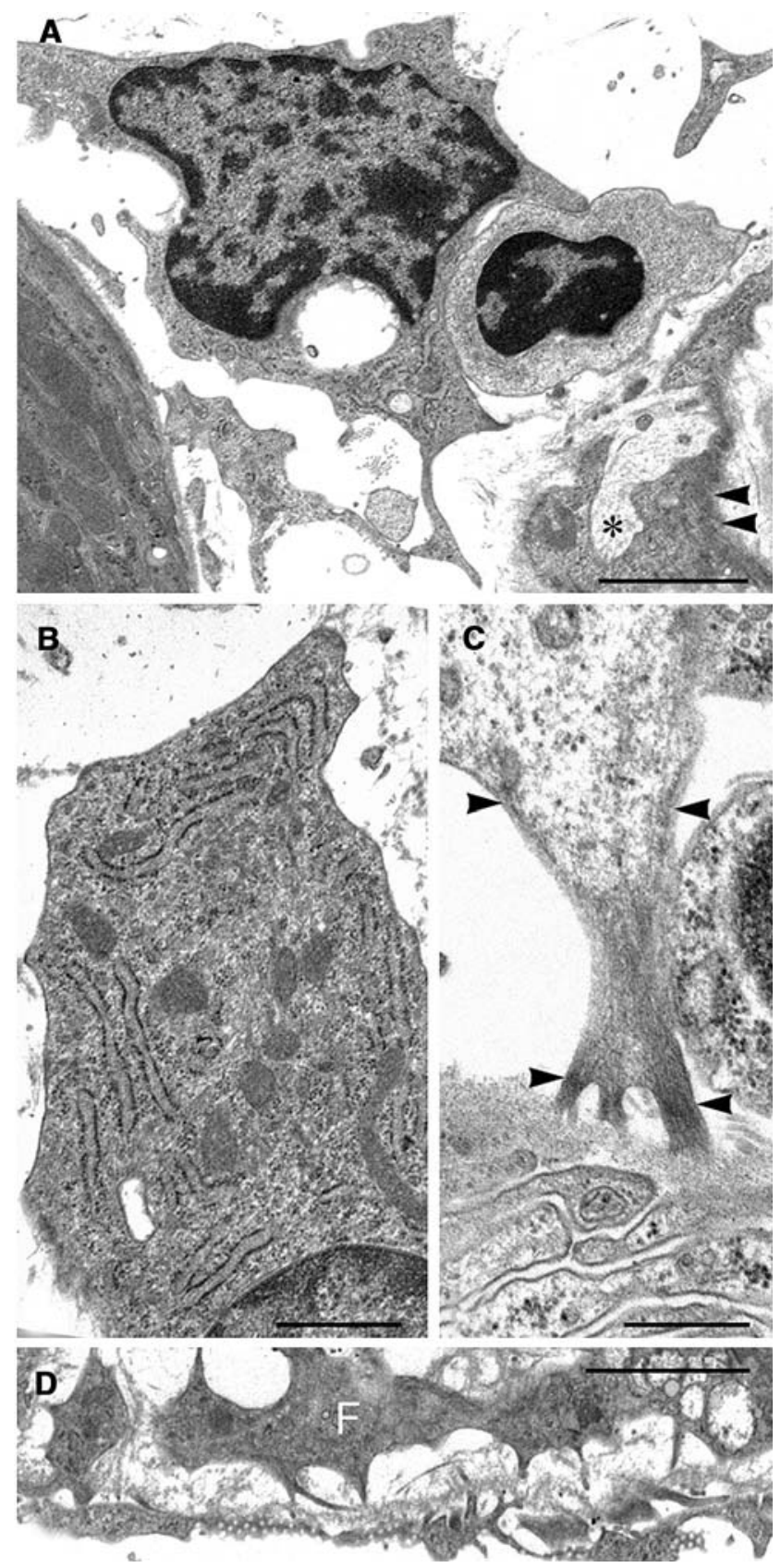

Fig. 5 Fibroblast in the cortical peritubular interstitium of a healthy mouse (transmission electron microscopy). a Stellate pericaryon with a thin cytoplasmic rim and large processes, and close juxtaposition to a lymphocyte; matrix, released by the fibroblast (asterisk); F-actin filaments beneath the plasma membrane (arrow head). b The abundant rough endoplasmatic reticulum (rER), mitochondria and Golgi apparatus are located in the large cell processes; the rER cisterns are densely studded with ribosomes and free ribosomes are frequent. $\mathbf{c}$ attachment to the basement membranes of tubules and capillaries frequently occurs by spine-like processes, densely filled with F-actin stress fibers (arrow heads). d Tangential sections of an endothelial cell and part of a fibroblast $(F)$, showing the anchoring of the fibroblast to the basement membrane by spine-like processes. Bars a $4 \mu \mathrm{m}$, b $1 \mu \mathrm{m}$, c $0.5 \mu \mathrm{m}, \mathbf{d} 2 \mu \mathrm{m}$ chemokines (van Kooten and Daha 2001) but as well by mechanical forces (Fujigaki et al. 2005).

Protein synthesis apparatus

The synthesis of collagen fibers (types I, III and VI), of unbanded microfilaments and of matrix is part of the scaffolding function by fibroblasts (Lemley and Kriz 1991). This function is mirrored by the prominent apparatus for protein synthesis. Indeed, the extensive rough endoplasmatic reticulum (rER) distinguishes fibroblasts from all other interstitial cells (Figs. 3, 5). The abundant meandering and anastomosing cisterns of the rough ER are particularly densely studded with ribosomes and show large profiles, which are filled by a flocculent, rather electron dense material. Free ribosomes are abundant. The rER cisterns are almost exclusively located in the large cytoplasmic processes of fibroblasts that might be quite distant from the pericaryon. The Golgi fields are usually located together with the rER in the periphery of the cells, where in electron microscopy the formation of collagen fibrils is often well detectable in the direct vicinity of the plasma membrane. This clearly designates the cell as fibroblast (Fig. 5). In "quiescent" fibroblasts the nucleus shows often angular profiles and reveals large amounts of heterochromatin condensations (Fig. 5), whereas in "activated" stages with increased matrix production the nucleus becomes enlarged, rounded and displays much more euchromatin (see below).

Other cell organelles are situated among the rER cisterns. Mitochondria are numerous. Fibroblasts can accumulate lipid droplets. These are not common in cortical fibroblasts of healthy kidneys; yet, they constitute a constant and characteristic feature of fibroblaststs in the medulla, in particular in the inner medulla. They appear also in cortical fibroblasts of anemic kidneys (Kaissling et al. 1993). Lysosomal bodies, which point to a phagocytotic capacity (Lullmann-Rauch 1987; Sundelin and Bohman 1990) are rarely observerd under control conditions.

Morphology of dendritic cells

Dendritic cells (DC) belong to the mononuclear phagocyte system, acting at the cross road of innate and adaptive immunity, self-tolerance, and tissue homeostasis (Soos et al. 2006; John and Nelson 2007). Interstitial DCs continually probe the surrounding environment through dendrite extension and readily respond to insults to the parenchyma they survey (Dong et al. 2005; Soos et al. 2006; John and Nelson 2007). DCs have been recognized by their expression of MHC class II (Fig. 6) and have been isolated on account of their membrane expression of CD11c (Kruger 


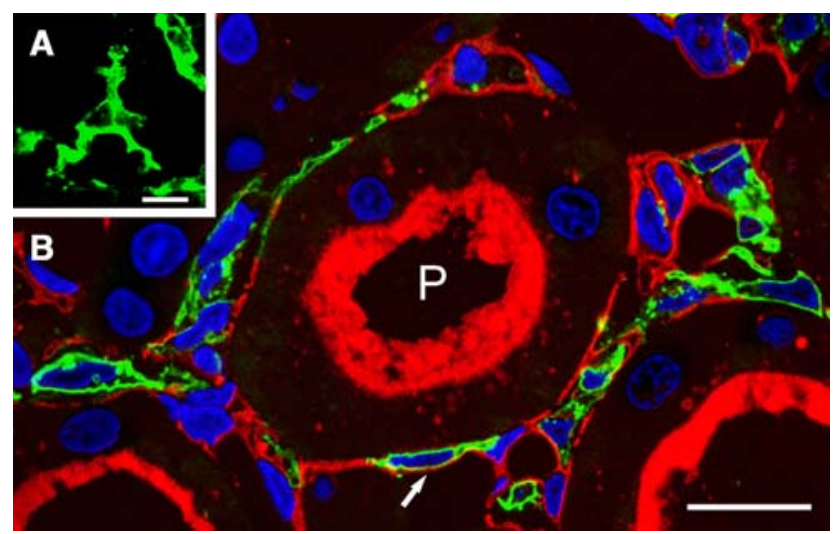

Fig. 6 Dendritic cells in the cortical peritubular interstitium. a Here comes the sentinel! dendritic cell (green) in the interstitial space. b $1 \mu \mathrm{m}$ cryostat section; dendritic cells express MHC class II (green), fibroblasts express $5^{\prime} \mathrm{NT}(\mathrm{red})$, nuclei are stained in blue. Note the juxtaposition of fibroblast processes (arrow) and dendritic cells. $P$ proximal tubule with brush border (red). Bar a $1 \mu \mathrm{m}$, b $10 \mu \mathrm{m}$

et al. 2004). In the healthy kidney DCs are present in their immature phenotype with comparingly low levels of MHC class II and of co-stimulatory proteins (Kruger et al. 2004), but with a high capacity for uptake of antigens (Dong et al. 2005). They lack typical phagocyte markers. Practically, the immuno-labelling for MHC class II or CD11c and in mice also for F4/80 allows easy detection of dendritic cells in the healthy and diseased kidney.

In the kidney, DCs form an organ-spanning network (Soos et al. 2006), which is narrowly intertwined with the fibroblast network (Fig. 2). Thus, dendritic cells and fibroblasts are usually found in strikingly close contact with each other (Figs. 6, 7) (Kaissling and Le Hir 1994; Kaissling et al. 1996). Because DCs constantly form and retract dendritic extensions the shape revealed in a tissue sections represents a "snap-shot". Usually dendritic cells appear stellate in tissue sections (Fig. 7). Unlike fibroblasts the pericaryon of dendritic cells is large and rounded, and confines a rounded nucleus and most cell organelles. Dendritic cells have, in comparison to infiltrating cells (macrophages, lymphocytes), more mitochondria, more rER, and a large Golgi apparatus (Fig. 7). Lysosomes are less apparent than in macrophages. The so-called Birbeck granules, which are characteristic for dendritic cells, are a special formation of the endocytotic compartment, serving as a loading compartment and/or reservoir of antigens before DC maturation (Fig. 7) (Mc Dermott et al. 2002). The rER of dendritic cells differs from that of fibroblasts. The cisterns are narrow, little ramified, and regionally lacks the dense studding of ribosomes and the lumen of the rER cisterns is electrolucent (Fig. 7). The intermediate filament protein vimentin is regularly present in the pericaryon of DCs whereas it is absent in fibroblasts in the healthy renal cortex.
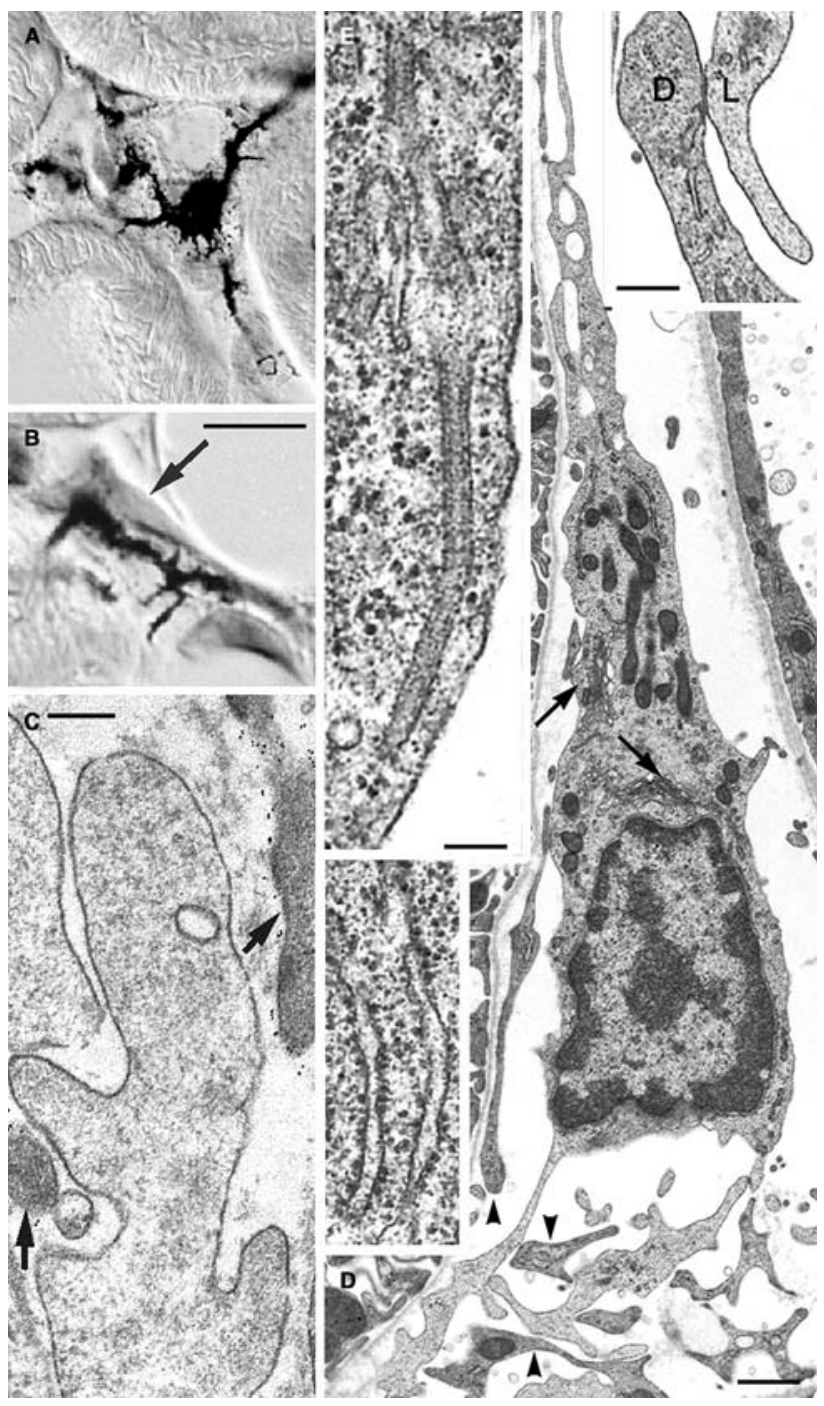

Fig. 7 Dendritic cells in the cortical peritubular interstium. a, b Cryostat sections, immunogold staining for MHC class II, showing dendritic cells, and differential interference contrast $(D I C)$. The processes of the dendritic cells have extensive contact with fibroblasts (arrow). c the peripheral processes of dendritic cells are virtually devoid of large cell organelles and appear lighter than the processes of the F-actin filament-displaying fibroblast processes (arrows), here labeled with immunogold for ecto-5'-nucleotidase. d The pericaryon displays a rounded nucleus, numerous mitochondria, Golgi apparatus (arrows) and rough endoplasmic reticulum (see insert 1); the cell processes are branched and appear much lighter than those of fibroblasts (arrowheads). Insert 2 adhesion between processes of a dendritic cell and of a lymphocyte. e Birbeck granule, in a dendritic cell. Bars a, b $10 \mu \mathrm{m}$; c $0.1 \mu \mathrm{m} ; \mathbf{d} 1 \mu \mathrm{m}$; insert $0.5 \mu \mathrm{m}$; e $0.01 \mu \mathrm{m}$

The broad ramified and flat "veil-like" processes, that often appear perforated like laces are largely devoid of cell organelles and they lack the prominent stuffing with F-actin filaments, characterizing fibroblasts. In addition they have long filiform processes, of approximately the same diameter as the filiform fibroblast processes. In transmission electron microscopy a distinction of fibroblast and DC 
processes is, however, possible without any marker. Due to the lack of F-actin the processes of dendritic cells appear always much less electron dense than the fibroblast processes (Fig. 7). The lack of the prominent F-actin skeleton is in line with the lack of junctional connections between DCs and tubules or vessels, in contrast to fibroblasts. However, frequently the plasma membranes of dendritic cells and of fibroblasts, or dendritic cells and lymphocytes form spots of membrane adhesions,so-called "kisses" (Fig. 7). Double immuno-staining using $5^{\prime} \mathrm{NT}$ for fibroblasts and MHC class II for dendritic cells allows an appreciation of the narrow intermingling of both cell types (Fig. 6), suggesting the possibility of extensive cross-talk between them.

Macrophages, lymphocytes and granulocytes

Macrophages and lymphocytes are rarely found in the healthy renal interstitium but they invade the interstitial spaces under inflammatory conditions (Eddy 2005). A large proportion of the invading mononuclear cells display, besides the established marker proteins (e.g. CD 45, CD3, CD4, CD 8; ED1, ED2, CD44), the cytosolic protein S100A4/FSP1 (Le Hir et al. 2005). Neutrophil granulocytes are found occasionally, basophil and eosinophil granulocates and plasma cells are rare in the healthy cortical renal interstitium.

Morphology of myofibroblasts

Any chronic inflammation of the interstitium goes along with the appearance of interstitial cells with a specific phenotype, the myofibroblasts. The myofibroblasts are a landmark of renal fibrosis which is the final common pathway for all chronic kidney diseases and is eventually associated with the loss of kidney function.

Functionally myofibroblasts resemble, on one hand, fibroblasts because of their matrix production and, on other hand, smooth muscle cells because of their contractility due to the presence of $\alpha \mathrm{SMA}$.

On account of structural criteria there exists a continuum from "quiescent" fibroblasts to "activated" myofibroblasts and intermediate forms between typical interstitial fibroblasts and myofibroblasts can be found (Picard et al. 2008).

By definition myofibroblasts are large stellate cells, but their appearances are extremely variable (Fig. 8). In contrast to normal fibroblasts their nucleus is generally rounded (Fig. 8) sometimes with indentations, and appears
Fig. 8 Gallery of myofibroblasts (transmission electron microscopy). Myofibroblasts show a heterogeneous morphology. a myofibroblasts after $24 \mathrm{~h}$ of ureter ligature with transitory features between a "quiescent" fibroblast with narrow rER (around the nucleus) and a typical myofibroblasts with inflated cisterns of rER (in the cellular process); $\mathbf{b} 2$ days after ureter ligature with largely inflated cisterns; $\mathbf{c}$ after 3 days showing a stellate shape; $\mathbf{d}$ after 3 days of ureter ligature. Bar $2 \mu \mathrm{m}$

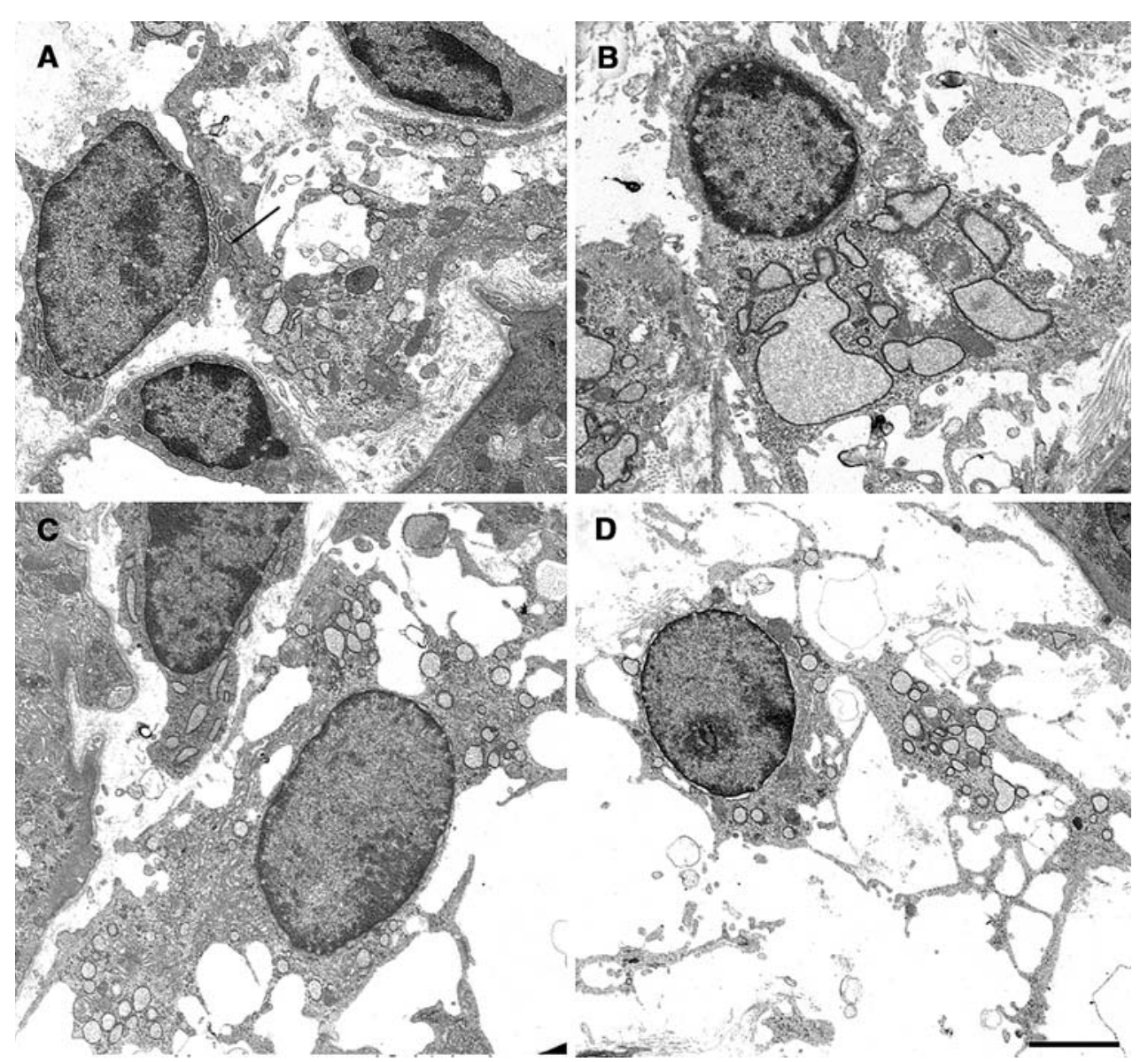


lighter than nuclei of "quiescent" fibroblasts, due to less heterochromatin condensations. It is surrounded by a broad cytoplasmic rim. Morphological evidence for increased production of matrix is the abundant $r E R$, most often with inflated cisterns (Figs. 8, 9). The latter are found in the large pericaryon and in the broad, extensively branched cytoplasmic processes. The accumulations of collagen fibrils in cellular indentations, and the occasional presence of an incomplete layer of basement membrane-like matrix on the cell surface manifest the enhanced matrix production by the cells (Fig. 9).

The hallmark of myofibroblasts is the presence of the $\alpha$ SMA (Desmouliere et al. 2005; Hinz 2007; Hinz et al. 2007) which builds bundles of microfilaments with dense bodies (Fig. 9). These bundles may run across the cytoplasm and are not necessarily associated with the plasma membrane, as the F-actin filaments in quiescent fibroblasts, and they are concentrated in cellular processes. The frequency of intercellular attachments by intermediate junctions and of hemidesmosome-like attachments to basement membranes of tubules and vessels is much higher than in quiescent fibroblasts.

Furthermore, the intermediate filament protein vimentin is expressed in myofibroblasts, but not in quiescent fibroblasts of adults. Desmin, another intermediate filament protein, has been described to be present in myofibroblasts (Maxwell et al. 1997); however, we and others (Essawy et al. 1997) never detected desmin in renal myofibroblasts.

\section{Role of fibroblasts in regulation of regional renal hemodynamics and in renal erythropoietin production}

The presence of $5^{\prime} \mathrm{NT}$ in cortical fibroblasts indicates that adenosine can be produced in the cortical interstitium. $5^{\prime} \mathrm{NT}$ is responsible for conversion of extracellular 5'-AMP to adenosine (Eltzschig et al. 2003). The bulk of extracellular 5'-AMP in kidney most probably originates from tubular cells and any disturbances in the energy balance of tubules might increase 5'-AMP levels in the interstitial
Fig. 9 Myofibroblast in the cortical peritubular interstitium in a rat kidney after 3 days of ureter ligature. a The rounded nucleus is surrounded by a large pericaryon, containing enlarged cisterns of rough endoplasmic reticulum (rER); $\alpha$ SMA (arrow) is detectabe traversing the cytoplasm; note the abundant fibrillar matrix in the surrounding of the cell. b Junction between myofibroblasts processes with stress-like F-actin filaments (asterisk) are frequent; basement membrane-like material is apposed to the plasmalemm ( $a r$ rows); insert bundle of $\alpha \mathrm{SMA}$ filaments with dense bodies ( $a r$ rows). c Inflated rER, filled with flocculent material. Bars $\mathbf{a} 2 \mu \mathrm{m}$; b, $\mathbf{c}$ and insert $0.5 \mu \mathrm{m}$
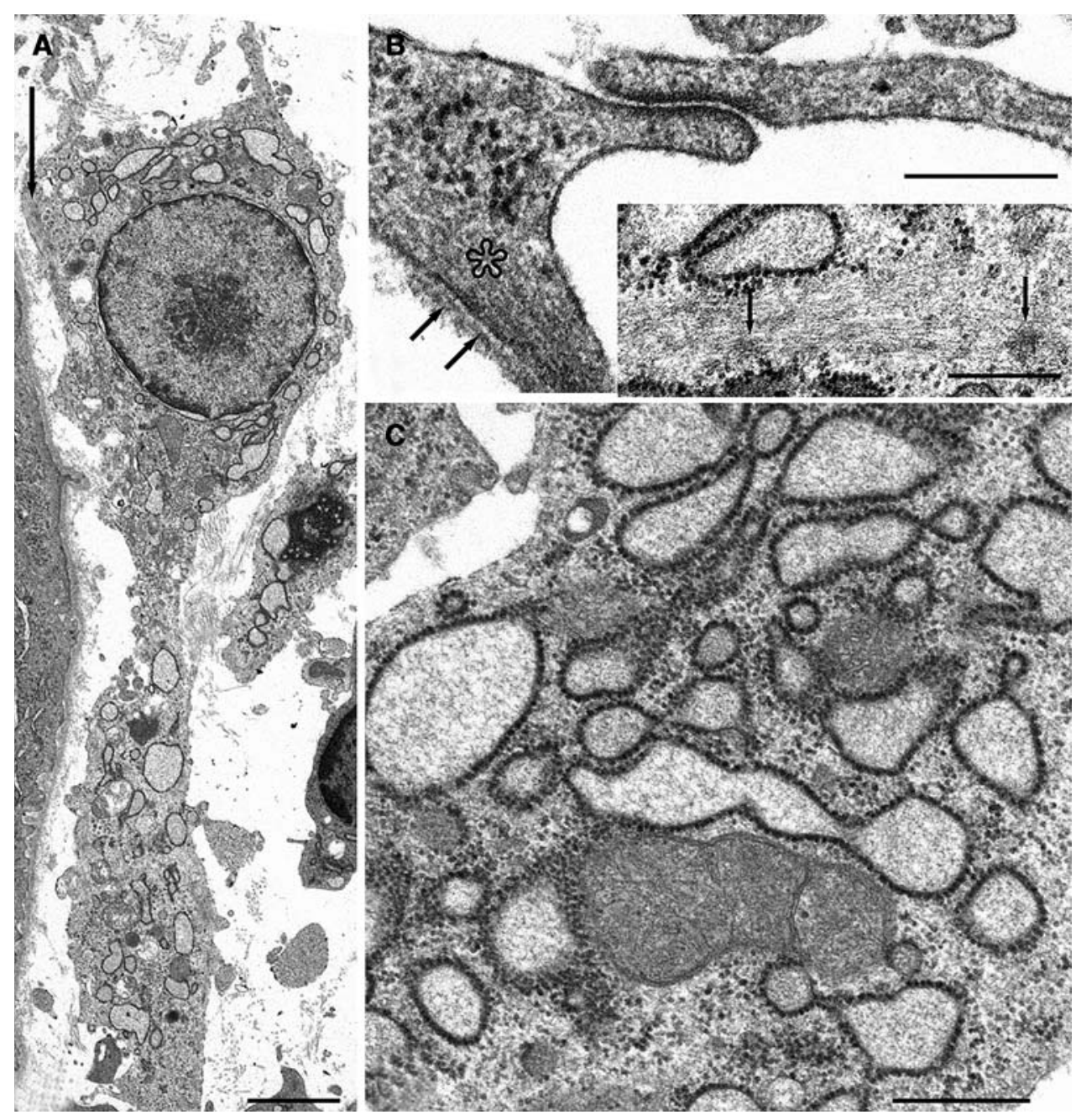
space (Le Hir and Kaissling 1993). Thus, hydrolysis of extracellular 5'-AMP by fibroblast 5'NT would elicit local adenosine-mediated responses, like adjustment of blood flow. Under inflammatory conditions also infiltrating activated polymorphonuclear neutrophils may contribute to the pool of interstitial $5^{\prime}$-AMP and adenosine might modulate inflammation (Linden 2006; Yang et al. 2006).

Adenosine adjusts blood supply to organ metabolism by regulating local hemodynamics (Vallon 2003). Thus, the particularly narrow sheathing of glomerular arterioles by 5'NT-positive fibroblasts (Gandhi et al. 1990) (Fig. 10) suggests a role in the regulation of glomerular blood flow. Indeed, studies on $5^{\prime} \mathrm{NT}$-deficient mice have confirmed that adenosine mediates the vascular response elicited by changes in $\mathrm{NaCl}$ concentration at the macula densa, thereby serving as an important regulator of glomerular filtration rate (Castrop et al. 2004). Due to the narrow apposition of thin $5^{\prime} \mathrm{NT}$-positive fibroblast processes to the thin capillary endothelia fibroblasts are often misinterpreted as endothelial cells in immunofluorescence (Vallon 2003) or they are designated as "pericytes". The soluble guanylyl cyclase (sGC), which is part of the NO-sGCcGMP signalling pathway associated with regulation of regional hemodynamics (Theilig et al. 2001), and a $b$-type cytochrome 558 as part of the neutrophil NADPH-oxidase (Bachmann and Ramasubbu 1997) have been localized in the cortical fibroblasts.

Extracellular adenosine has been widely implicated in adaptive responses to hypoxia (Eltzschig et al. 2003; Grenz et al. 2007). The role of the fibroblasts in the adaptive response to systemic hypoxia is further highlighted by the discovery that renal erythropoietin is synthesized exclusively by $5^{\prime} \mathrm{NT}$-positive renal fibroblasts (Bachmann et al. 1993; Maxwell et al. 1993; Fisher et al. 1996). The kidneys adjust their erythropoietin production to changes in oxygen supply (Maxwell 2003). Regulation of erythropoietin production and transcription of erythropoietin are mediated by hypoxia-inducible factor (HIF Hif-2 $\alpha$ ) (Maxwell 2003) which has been located as well to 5'NT-positve fibroblasts (Rosenberger et al. 2003, 2005).

In kidneys of normoxic rats and mice erythropoietinmRNA is detected only in the 5'NT-positive peritubular fibroblasts in the deep cortex. At this level 5'NT expression by peritubular fibroblasts is highest and it decreases towards the renal surface. Both, hypoxia and anemia, involve a progressive recruitment of additional interstitial fibroblasts for erythropoietin production in a pattern that spreads from the deep cortex toward the capsule (Eckardt et al. 1993). In parallel the $5^{\prime} \mathrm{NT}$ activity by the peritubular fibroblasts increases towards the capsule (Kaissling et al. 1993). This points again to an obvious link between $5^{\prime} \mathrm{NT}$ expression (or adenosine) and erythropoietin synthesis,
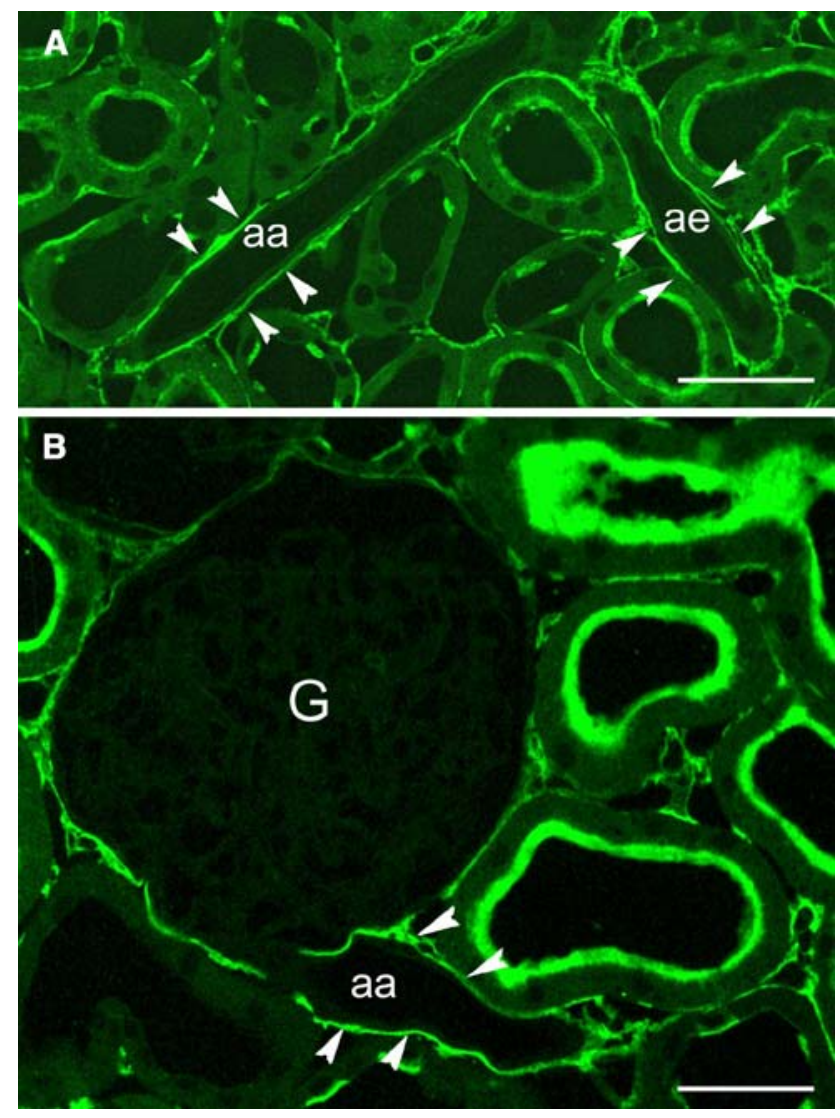

Fig. 10 Glomerular arterioles are ensheathed by ecto-5' -nucleotidaseexpressing processes (arrowheads); 5'NT (green); aa afferent arteriole, ae efferent arteriole, $G$ Glomerulus. Bars a $50 \mu \mathrm{m}$; b $20 \mu \mathrm{m}$

which also has been confirmed in a fibroblast cell line (Plotkin and Goligorsky 2006). The details of this link are, however, still inexplicit. Interestingly, Ito-cells (or fat-storing cells) in the liver, which express 5'NT (Schmid et al. 1994) and which resemble morphologically in all respects to the renal cortical fibroblasts, also produce erythropoietin (Maxwell et al. 1994).

The phenotype of fibroblasts changes in acutely (1 week) (Kaissling et al. 1993) and chronically anemic rats (Kurtz et al. 1989). The cortical fibroblasts increase in size, reveal strikingly larger nuclei and frequent lipid droplets in the enlarged pericaryon and in peripheral cell processes. In addition to a few sharply outlined large cell processes they display an increased amount of thin, extensively ramified very long processes (Eckardt et al. 1993; Kaissling et al. 1993). The erythropoietin-producing cells show a much higher 5'NT activity in their plasma membrane (Fig. 11) and are consistently negative for $\alpha$ SMA (Maxwell et al. 1993; Plotkin and Goligorsky 2006). Under chronic anemia ( 3 months) the plasma membrane surface of the $5^{\prime}$ NT-positive fibroblasts increases by formation of additional cell processes (Fig. 11) (Le Hir et al. 1989, 1991). 

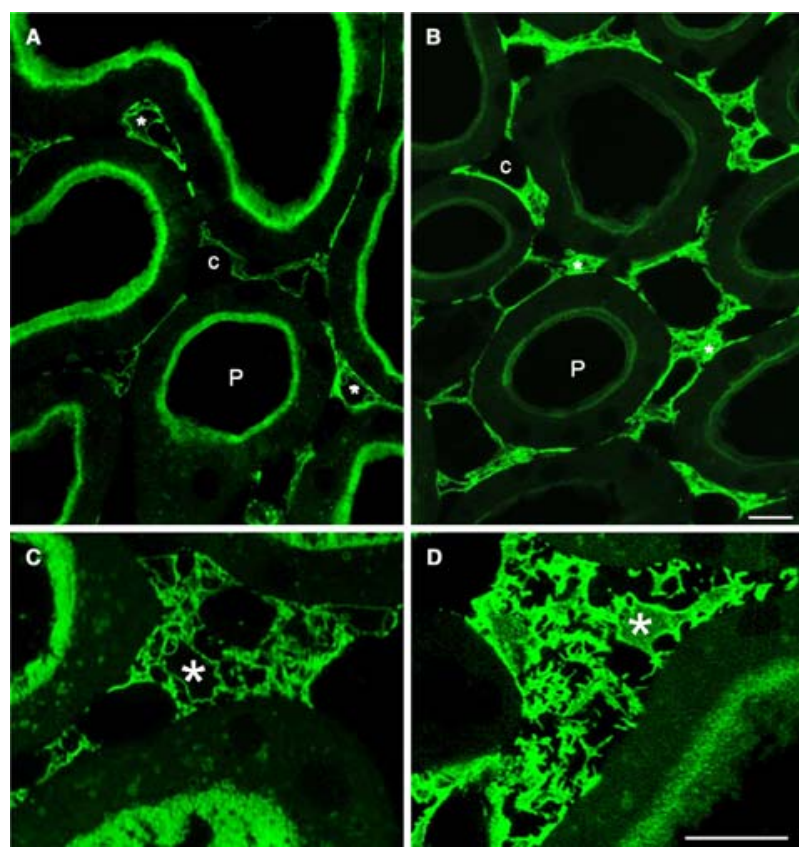

Fig. 11 Ecto-5'-nucleotidase in the renal cortex of a normemic $(\mathbf{a}, \mathbf{c})$ and an anemic $(\mathbf{b}, \mathbf{d})$ rat $(1 \mu \mathrm{m}$ cryostat sections; $P$ proximal tubules; $c$ capillaries). Fibroblasts (stars) in anemic rats reveal a markedly increased 5'NT expression and more cellular processes. Bars $10 \mu \mathrm{m}$

\section{Role of fibroblasts in chronic renal failure}

Fibrosis is the morphological hallmark of chronic renal failure. It is characterized by an exaggerated accumulation of fibrous collagens, by an increased incidence of interstitial cells in the renal interstitium and by the emergence of myofibroblasts.

\section{Origin of fibroblasts/myofibroblsts in renal fibrosis}

Until the late 1990s it was generally assumed that myofibroblasts developed by proliferation and differentiation from resident fibroblasts (Bulger and Nagle 1973). Yet, this concept has been challenged in more recent studies. The difficulty to detect interstitial fibroblasts in the kidney, discussed above, resulted in the erroneous belief that fibroblasts are sparse in the healthy kidney. Therefore, sources other than the resident fibroblasts population were proposed for the numerous myofibroblasts found in various models of kidney disease. Three origins have been considered.

\section{Epithelial-mesenchymal transition (EMT)}

The hypothesis that in renal diseases, fibroblasts are generated via epithelial-mesenchymal transition (EMT) grounds on two observations. First, in many instances tubular cells lose some of their epithelial features and acquire a "mesen- chymal" appearance. Second, in such instances some tubular cells express proteins, which are considered specific for fibroblasts/myofibroblasts, namely fibroblasts-specific protein-1 (FSP1) (Zeisberg et al. 2001; Iwano et al. 2002), heat shock protein HSP47 (Iwano et al. 2002) and $\alpha$ SMA (Liu 2004). However the interpretation of the latter findings requires some caution. FSP1 is not a reliable fibroblast marker (Le Hir et al. 2005). HSP47 is supposed fibroblastspecific because it is a chaperone for collagens. However it is not a chaperone for fibrous collagens only. Accordingly, accumulation of HSP47 was observed in tubular cells, which produced excessive amounts of collagen type IV in a model of partial nephrectomy (Kimura et al. 2005). The occasional expression of $\alpha \mathrm{SMA}$ in some tubular cells in models or renal disease is intriguing. However, it remains to be proven that $\alpha$ SMA-positive tubular cells acquire the most characteristic function of fibroblasts/myofibroblasts, namely the production of collagen fibers.

In some experimental models, like 5/6 nephrectomy (Kimura et al. 2005), DCT lesion with thiazide diuretics (Le Hir et al. 2005) and UUO (Picard et al. 2008), accumulation of $\alpha$ SMA-positive interstitial cells was observed whereas the tubules remained $\alpha$ SMA-negative. The same observation was made in biopsies of patients with nephritic syndrome (Kuusniemi et al. 2005). At least in those instances myofibroblasts did not appear to originate via EMT.

\section{Bone marrow $(\mathrm{BM})$ origin}

There is evidence from animal models and from studies with $\mathrm{BM}$ transplant recipients that circulating precursors from BM origin give rise to fibroblasts/myofibroblasts in various organs in adults (Quan et al. 2004; Desmouliere et al. 2005; Hinz et al. 2007). Studies using transgenic rodents have shown a BM origin of a limited fraction of renal myofibroblasts after ischemia/reperfusion injury (Broekema et al. 2007) and in the model of adriamycininduced chronic renal failure (Li et al. 2007).

Proliferation and differentiation of resident fibroblasts

It is widely accepted that under conditions leading to fibrosis in various organs fibroblasts transform into myofibroblasts, and both fibroblasts and myofibroblasts proliferate (Desmouliere et al. 2005; Hinz 2007; Hinz et al. 2007). Apparently, that straightforward view of the cellular basis of fibrosis has not much attracted the interest of investigators in the field of renal pathophysiology. Thus, very few studies have analyzed the response of resident fibroblasts to renal diseases.

In the following we will discuss a few morphological investigations, which reveal a gradual transformation of 
fibroblasts to myofibroblasts. In the experimental model of unilateral ureter obstruction we investigated the phenotype of fibroblasts during the first 4 days after ureter ligation in the rat. Already on day 1 the $5^{\prime}$ NT-positive fibroblasts showed de novo expression of $\alpha \mathrm{SMA}$, this increased progressively during the experiment (Figs. 12, 13). The expression of $5^{\prime} \mathrm{NT}$ decreased at the same time. Furthermore, we observed a massive increase in the mitotic rate in interstitial cells. Mitoses were present in fibroblasts (Fig. 14), myofibroblasts and mononuclear cells. The changes in fibroblast morphology were accompanied by enlargement of the intercellular space and deposition of collagen I (Picard et al. 2008).

In the thiazide-induced model of distal tubular lesion (Loffing et al. 1996) the time course of events resulting in the peritubular inflammation and appearance of myofibroblasts can be particularly well followed. Accumulations of dendritic cells around injured tubular profiles (Fig. 15) were observed after $24 \mathrm{~h}$ and massive invasion of mononuclear cells started after about $36 \mathrm{~h}$ as well as the morphological changes in peritubular fibroblasts (Fig. 15). Within three days transformation of fibroblasts into myofibroblasts was indicated by de-novo expression of $\alpha \mathrm{SMA}$ and vimentin, an increased complexity of cell shape, an expansion of the RER and an increased incidence of intercellular junctions (Figs. 15, 16) (Le Hir et al. 2005). In contrast to UUO, only fibroblasts in the vicinity of DCTs were affected after thiazide treatment (Fig. 17). That process was interpreted as a transformation of resident fibroblasts in myofibroblasts. Mitotic figures were frequent in fibroblasts and myofibroblasts (Le Hir et al. 2005).

Maxwell et al. (1997) previously observed an expression of $\alpha \mathrm{SMA}$ in $5^{\prime} \mathrm{NT}$-positive fibroblasts in UUO and after mechanical lesions (needlestick) in mice kidneys, which was associated with, first, a decrease in $5^{\prime} \mathrm{NT}$, and second, a reduced capacity of the fibroblasts to respond with erythropoietin production under hypoxia. Proliferation of interstitial cells has also been described in the model of UUO (Duymelinck et al. 2000) and in another model of renal fibrosis induced by aristolochic acid (Pozdzik et al. 2008).

Mechanical stress seems to play a central role in the transformation of fibroblasts into myofibroblasts after ura-
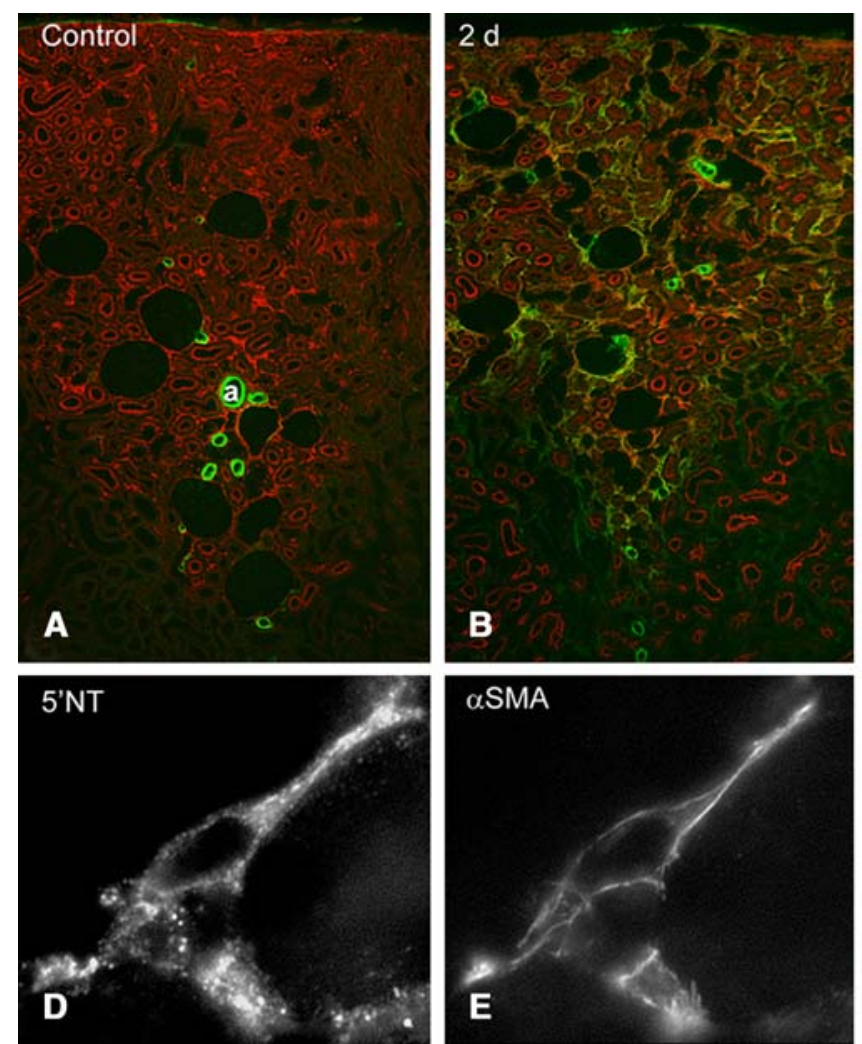
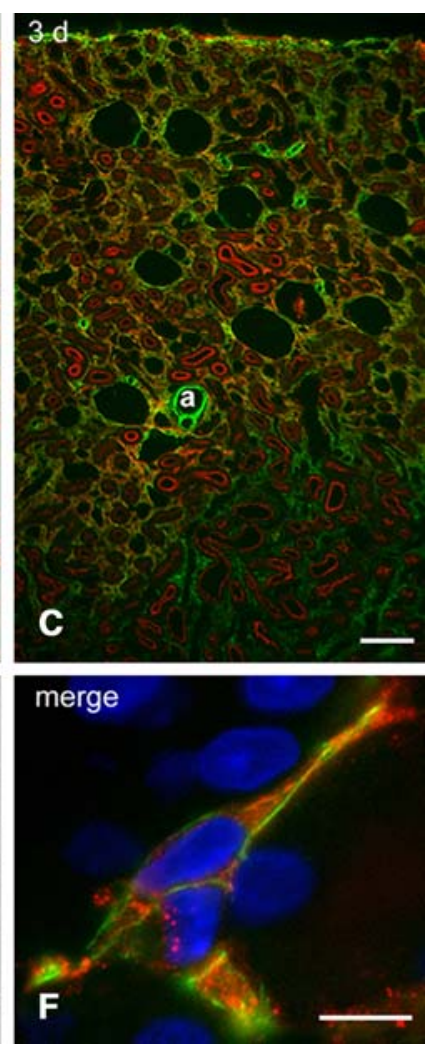

Fig. 12 Renal cortex in sham-operated (a) and in ureter-ligated kidneys $(\mathbf{b}, \mathbf{c})\left(3 \mu \mathrm{m}\right.$ cryostat sections, red ecto-5'nucleotidase $\left(5^{\prime} \mathrm{NT}\right)$, green alpha smooth muscle actin ( $\alpha \mathrm{SMA})$, blue cell nuclei). In controls (a) the interstitium and the brush border of proximal tubules are strongly labeled by $5^{\prime} \mathrm{NT}, \alpha \mathrm{SMA}$ labels exclusively arterial vessels $(a)$. After 2 days of ureter ligature (b) interstitial $5^{\prime} \mathrm{NT}$ staining decreases, whereas $\alpha$ SMA appears and becomes increasingly prominent throughout the cortex after 3 days (c). Interstitial $\alpha$ SMA-staining progressively appears also in the outer stripe of the outer medulla, seen at the bottom of the images. d-f Interstitial fibroblast in ureter-ligated kidney after 2 days. The weakly expressed $5^{\prime} \mathrm{NT}$ is distributed in a granular manner over the plasma membrane and the cytoplasm, $\alpha \mathrm{SMA}$ is apparent along the plasma membrane and in the cellular processes. Bar a-c $100 \mu \mathrm{m}$, d-f $10 \mu \mathrm{m}$ (from Picard et al. 2008) 
Fig. 13 Renal cortex after 4 days of ureter ligation [ $3 \mu \mathrm{m}$ cryostat sections; red ecto- $5^{\prime}$ nucleotidase $\left(5^{\prime} \mathrm{NT}\right)$, green alpha smooth muscle actin $(\alpha \mathrm{S}$ MA), blue nuclei]. a Merge of channels, (b) 5'NT, (c) $\alpha \mathrm{SMA}$; the framed area (1) comprises interstitium with still high $5^{\prime} \mathrm{NT}$ and faint $\alpha$ SMA staining, adjacent to rather intact tubules showing open lumina, the framed area (2) comprises interstitium with strong $\alpha \mathrm{SMA}$ and faint $5^{\prime} \mathrm{NT}$ staining, adjacent to collapsed tubules, showing signs of tubular atrophy. Bar $\mathbf{a}-\mathbf{c}$ $\sim 100 \mu \mathrm{m} ; 1,2 \sim 10 \mu \mathrm{m}$ (from Picard et al. 2008)
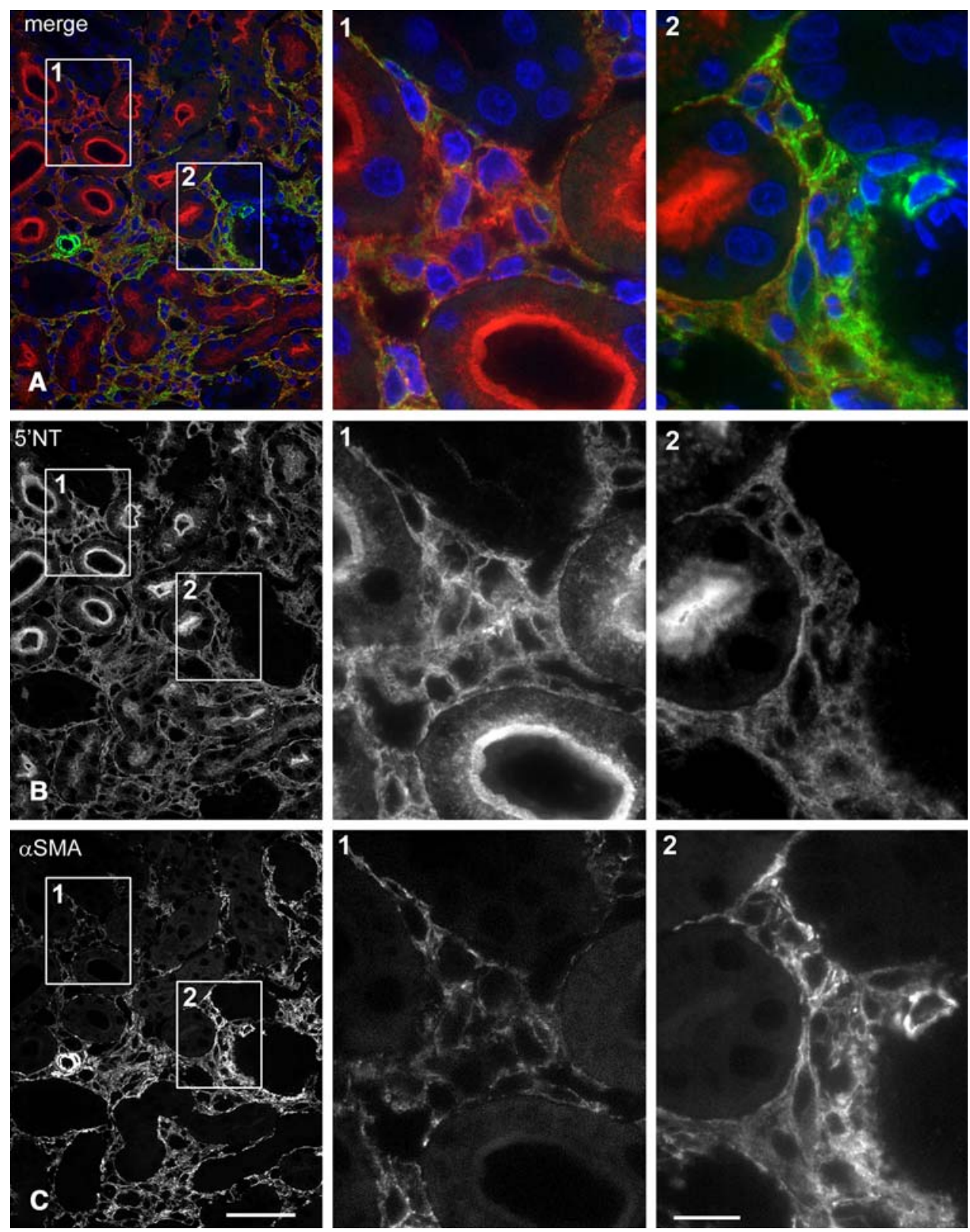

nyl acetate-induced tubular lesion (Fujigaki et al. 2005). The dilatation or shrinkage of tubules likely exerts a tension on the fibroblasts that are directly attached to damaged tubules. Mechanical forces could be transmitted to further fibroblasts by cell-cell contacts.

Fibrosis and nephron loss: which comes first?

The often massive extent of fibrosis in chronic renal failure unavoidably suggests that fibrosis might be responsible for the destruction of nephrons. Accordingly, in the case of glomerular diseases, the most common cause of chonic renal failure, it has been proposed that proteinuria elicits fibrosis via the release of profibrotic factors by tubular cells. Tubular degeneration would then be a consequence of fibrosis (Remuzzi and Bertani 1998; Meyer 2003; Eddy 2005). That view is widely accepted but not unchallenged. Indeed, morphological observations suggest that tubular degeneration may be a direct consequence of the encroachment of the glomerular lesion on the tubule (Kriz et al.

Fig. 16 Focal peritubular inflammation, associated with injured distal tubules $(D)$ in rats thiazide-treated for $72 \mathrm{~h} . \mathbf{a} 1 \mu \mathrm{m}$ Epon section; accumulation of interstitial cells around a DCT profile with degenerating epithelial cells, the downstream connecting tubule (CNT) segment and the surrounding interstitium is intact; b-d $1 \mu \mathrm{m}$ cryostat sections; (b) dendritic cells (MHC class II, green) and 5'NT-labeled fibroblasts (red) adjacent injured distal tubule; (c) vimentin (green) in mononuclear cells (plus) and in 5'NT-positive (red) fibroblasts (arrows); weak expression of vimentin also in the degenerating distal tubular epithelial cells; (d) some fibroblasts (arrows) show reduced 5'NT (red); MHC IIlabeled dendritic cells (green). Bar $10 \mu \mathrm{m}$ 
Fig. 14 Mitotic cells in the peritubular interstitium in rat kidneys after 1 day (a) and 2 days (b) of ureter-ligation ( $3 \mu \mathrm{m}$ cryostat sections; green $\alpha \mathrm{SMA}$, red $5^{\prime} \mathrm{NT}$, blue nuclei). The mitotic cell in a heavily expresses $5^{\prime} \mathrm{NT}$ and faintly $\alpha$ SMA, the adjacent cell shows strong $\alpha$ SMA and faint $5^{\prime} \mathrm{NT}$ staining. The 2 mitotic cells in b display strong staining for $\alpha \mathrm{SMA}$ along the plasma membrane and in the cell processes, $5^{\prime} \mathrm{NT}$ staining is weak, granular and is seen over the cytoplasm. Bar $10 \mu \mathrm{m}$ (from Picard et al. 2008)
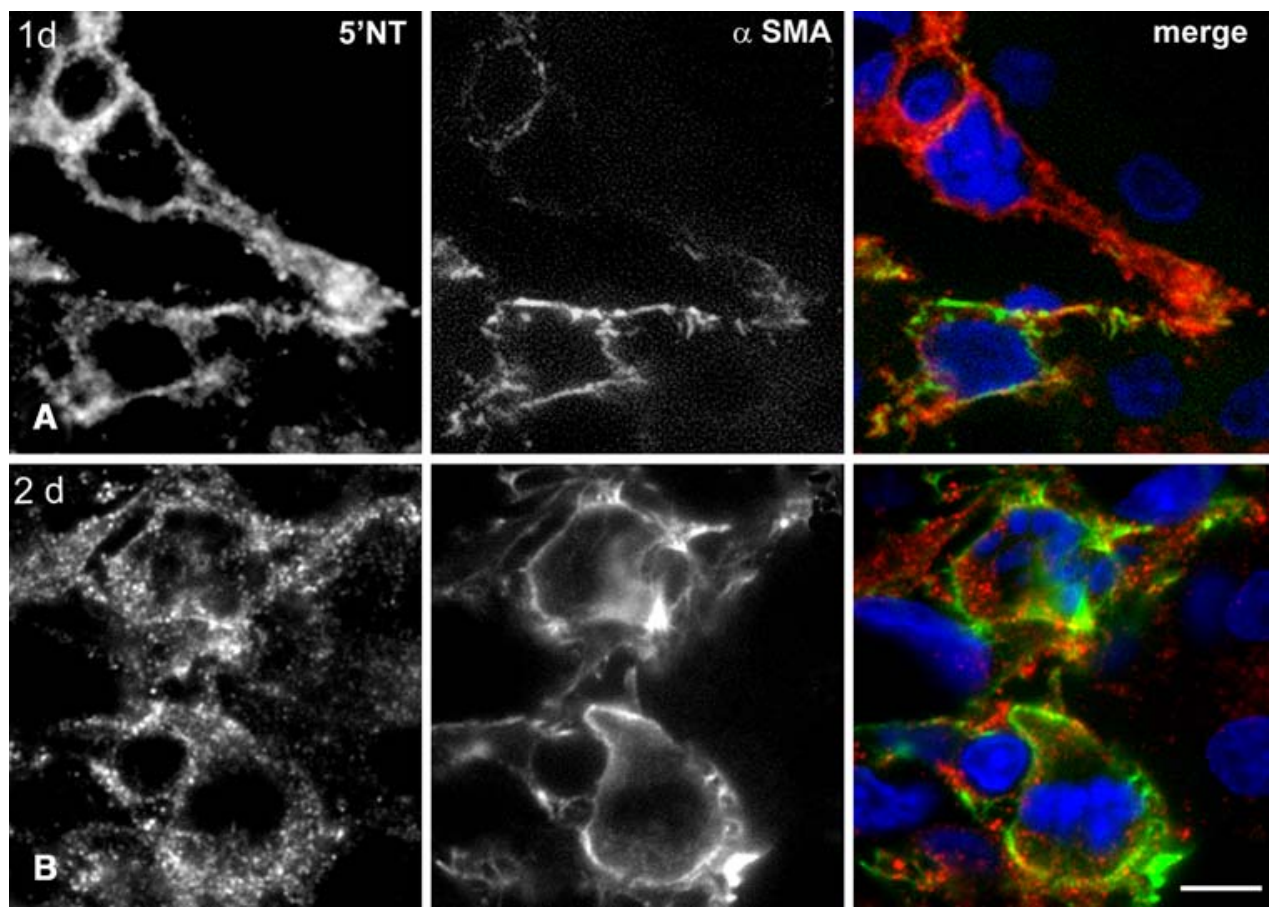

2001, 2003; Bertani et al. 2002; Le Hir and Besse-Eschmann 2003; Kriz and LeHir 2005).

In the vast majority of chronic renal diseases there is a mix of tubular, glomerular and vascular alterations mostly accompanied by interstitial inflammation and fibrosis. Obviously, in such situations, it is difficult to decide whether the activation and transformation of fibroblasts is the cause or the consequence of tubular lesions. Therefore it is particularly interesting that in a few models fibrosis appears to be induced by a primary tubular insult. As described above the lesion induced by thiazide diuretics in the DCT in the rat induces an inflammatory reaction and a transformation of fibroblasts into myofibroblasts, which are strictly associated with the injured DCT (Loffing et al. 1996; Le Hir et al. 2005). In the kidney only DCT cells express the transporter NCC, which is the binding site for thiazide diuretics. In this model the fibrotic process came to a halt when under continued metolazone application the NCC-expressing cells were eliminated by apoptosis.
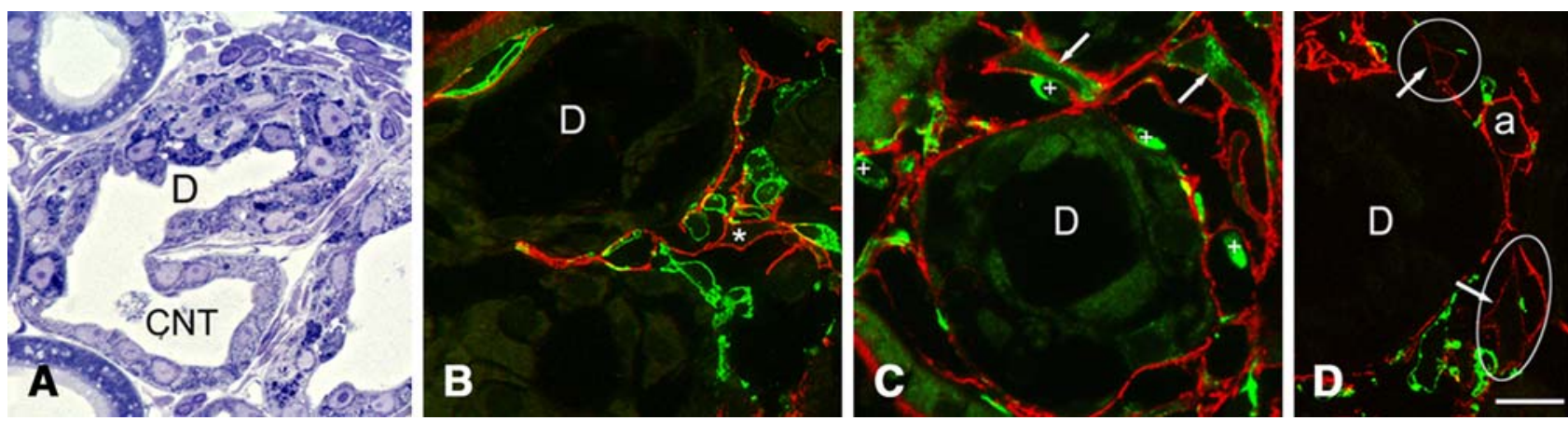


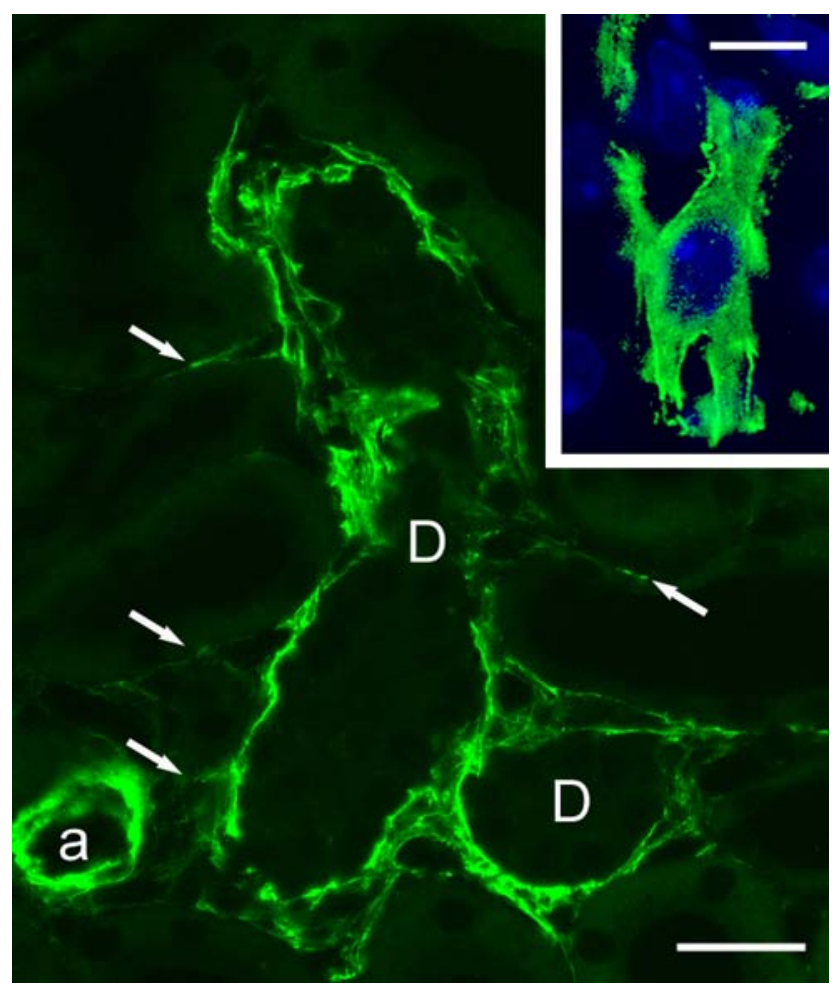

Fig. 17 Up-regulation of alpha smooth muscle actin in the interstitium surrounding injured distal tubular profiles $(D)$ of a rat treated for $72 \mathrm{~h}$ with a thiazide-diuretic ( $5 \mu \mathrm{m}$ cryostat section). Fibroblasts in extensive contact with the injured tubule show the strongest fluorescence for $\alpha$ SMA. More distant fibroblasts, which appear/are connected to the area of injury by cellular processes (arrows), show a weaker upregulation of $\alpha \mathrm{SMA} ; a$ arteriole. Insert close view of an interstitial $\alpha \mathrm{SMA}$ positive fibroblast. Bars $20 \mu \mathrm{m}$; insert $10 \mu \mathrm{m}$

A similar specific association of fibrotic processes with injured tubules was found in other models, in which there is little doubt that the experimental protocol affects primarily tubular cells. Local interstitial fibrosis was observed mainly around distal tubules after treatment with lithium (Zhu et al. 1996). Substances, which are toxic to specific segments of the proximal tubules, induced fibrosis specifically around the affected segments (Fujigaki et al. 2005; Pozdzik et al. 2008).

In those models of primary tubular lesion the association in localization and in time between tubular damages and interstitial responses suggests that fibrosis might represent a repair process. Interestingly, inhibition of transformation of fibroblasts into myofibroblasts after induction of acute renal failure with uranyl acetate resulted in aggravation of renal dysfunction and inhibition of renal repair (Fujigaki et al. 2005).

\section{Conclusion}

The cortical fibroblasts contribute essentially to renal functions, not only as skeleton of the organ but also by produc- ing regulatory substances such as, e.g. adenosine and erythropoietin. In response to tubular lesions fibroblasts proliferate and transform into myofibroblasts, thus initiating fibrosis. The role of that process in renal diseases remains to be elucidated. On one hand, fibrosis might contribute to the deterioration of renal function. On other hand, in the same way as in other organs, fibrosis in the kidney might contribute to repair by containing inflammation and by preserving the organ architecture. Experimental models in which fibrosis is induced by lesions to specific tubular cell types appear particularly promising for the study of the cross-talk between tubular cells and interstitial cells in disease.

\section{References}

Alcorn D, Maric C, McCausland J (1999) Development of the renal interstitium. Pediatr Nephrol 13:347-354

Bachmann S, Ramasubbu K (1997) Immunohistochemical colocalization of the alpha-subunit of neutrophil NADPH oxidase and ecto5 '-nucleotidase in kidney and liver. Kidney Int 51:479-482

Bachmann S, Le Hir M, Eckardt KU (1993) Co-localization of erythropoietin mRNA and ecto-5'-nucleotidase immunoreactivity in peritubular cells of rat renal cortex indicates that fibroblasts produce erythropoietin. J Histochem Cytochem 41:335-341

Bertani T, Mazzucco G, Monga G (2002) How glomerular extracapillary proliferation might lead to loss of renal function: light microscopic and immunohistochemical investigation. Nephron 91:74-78

Broekema M, Harmsen MC, van Luyn MJ, Koerts JA, Petersen AH, van Kooten TG, van Goor H, Navis G, Popa ER (2007) Bone marrow-derived myofibroblasts contribute to the renal interstitial myofibroblast population and produce procollagen I after ischemia/reperfusion in rats. J Am Soc Nephrol 18:165-175

Bulger RE, Nagle RB (1973) Ultrastructure of the interstitium in the rabbit kidney. Am J Anat 136:183-203

Castrop H, Huang Y, Hashimoto S, Mizel D, Hansen P, Theilig F, Bachmann S, Deng C, Briggs J, Schnermann J (2004) Impairment of tubuloglomerular feedback regulation of GFR in ecto-5' -nucleotidase/CD73-deficient mice. J Clin Invest 114:634-642

Davies BR, Davies MP, Gibbs FE, Barraclough R, Rudland PS (1993) Induction of the metastatic phenotype by transfection of a benign rat mammary epithelial cell line with the gene for $\mathrm{p} 9 \mathrm{Ka}$, a rat calcium-binding protein, but not with the oncogene EJ-ras-1. Oncogene 8:999-1008

Dawson TP, Gandhi R, Le Hir M, Kaissling B (1989) Ecto-5'-nucleotidase: localization in rat kidney by light microscopic histochemical and immunohistochemical methods. J Histochem Cytochem 37:39-47

Desmouliere A, Chaponnier C, Gabbiani G (2005) Tissue repair, contraction, and the myofibroblast. Wound Repair Regen 13:7-12

Dong X, Swaminathan S, Bachman LA, Croatt AJ, Nath KA, Griffin MD (2005) Antigen presentation by dendritic cells in renal lymph nodes is linked to systemic and local injury to the kidney. Kidney Int 68:1096-1108

Duymelinck C, Dauwe SE, De Greef KE, Ysebaert DK, Verpooten GA, De Broe ME (2000) TIMP-1 gene expression and PAI-1 antigen after unilateral ureteral obstruction in the adult male rat. Kidney Int 58:1186-1201

Eckardt KU, Koury ST, Tan CC, Schuster SJ, Kaissling B, Ratcliffe PJ, Kurtz A (1993) Distribution of erythropoietin producing cells in rat kidneys during hypoxic hypoxia. Kidney Int 43:815-823

Eddy AA (2005) Can renal fibrosis be reversed? Pediatr Nephrol 20:1369-1375 
Ekblom P, Weller A (1991) Ontogeny of tubulointerstitial cells. Kidney Int 39:394-400

Eltzschig HK, Ibla JC, Furuta GT, Leonard MO, Jacobson KA, Enjyoji K, Robson SC, Colgan SP (2003) Coordinated adenine nucleotide phosphohydrolysis and nucleoside signaling in posthypoxic endothelium: role of ectonucleotidases and adenosine A2B receptors. J Exp Med 198:783-796

Essawy M, Soylemezoglu O, Muchaneta-Kubara EC, Shortland J, Brown CB, el Nahas AM (1997) Myofibroblasts and the progression of diabetic nephropathy. Nephrol Dial Transplant 12:43-50

Fisher JW, Koury S, Ducey T, Mendel S (1996) Erythropoietin production by interstitial cells of hypoxic monkey kidneys. Br J Haematol 95:27-32

Fujigaki Y, Muranaka Y, Sun D, Goto T, Zhou H, Sakakima M, Fukasawa H, Yonemura K, Yamamoto T, Hishida A (2005) Transient myofibroblast differentiation of interstitial fibroblastic cells relevant to tubular dilatation in uranyl acetate-induced acute renal failure in rats. Virchows Arch 446:164-176

Gandhi R, Le Hir M, Kaissling B (1990) Immunolocalization of ecto5 '-nucleotidase in the kidney by a monoclonal antibody. Histochemistry 95:165-174

Garrett SC, Varney KM, Weber DJ, Bresnick AR (2006) S100A4, a mediator of metastasis. J Biol Chem 281:677-680

Garrett SC, Hodgson L, Rybin A, Toutchkine A, Hahn KM, Lawrence DS, Bresnick AR (2008) A biosensor of S100A4 metastasis factor activation: inhibitor screening and cellular activation dynamics. Biochemistry 47:986-996

Gibbs FE, Wilkinson MC, Rudland PS, Barraclough R (1994) Interactions in vitro of $\mathrm{p} 9 \mathrm{Ka}$, the rat S-100-related, metastasis-inducing, calcium-binding protein. J Biol Chem 269:18992-18999

Grenz A, Zhang H, Eckle T, Mittelbronn M, Wehrmann M, Kohle C, Kloor D, Thompson LF, Osswald H, Eltzschig HK (2007) Protective role of ecto-5' ${ }^{\prime}$-nucleotidase (CD73) in renal ischemia. J Am Soc Nephrol 18:833-845

Hashizume T, Imayama S, Hori Y (1992) Scanning electron microscopic study on dendritic cells and fibroblasts in connective tissue. J Electron Microsc (Tokyo) 41:434-437

Hatini V, Huh SO, Herzlinger D, Soares VC, Lai E (1996) Essential role of stromal mesenchyme in kidney morphogenesis revealed by targeted disruption of winged helix transcription factor BF-2. Genes Dev 10:1467-1478

Hinz B (2007) Formation and function of the myofibroblast during tissue repair. J Invest Dermatol 127:526-537

Hinz B, Phan SH, Thannickal VJ, Galli A, Bochaton-Piallat ML, Gabbiani G (2007) The myofibroblast. One function, multiple origins. Am J Pathol

Ina K, Kitamura H, Tatsukawa S, Takayama T, Fujikura Y, Shimada T (2002) Transformation of interstitial fibroblasts and tubulointerstitial fibrosis in diabetic nephropathy. Med Electron Microsc 35:87-95

Inoue T, Plieth D, Venkov CD, Xu C, Neilson EG (2005) Antibodies against macrophages that overlap in specificity with fibroblasts. Kidney Int 67:2488-2493

Itaranta P, Chi L, Seppanen T, Niku M, Tuukkanen J, Peltoketo H, Vainio S (2006) Wnt-4 signaling is involved in the control of smooth muscle cell fate via Bmp-4 in the medullary stroma of the developing kidney. Dev Biol 293:473-483

Iwano M, Plieth D, Danoff TM, Xue C, Okada H, Neilson EG (2002) Evidence that fibroblasts derive from epithelium during tissue fibrosis. J Clin Invest 110:341-350

John R, Nelson PJ (2007) Dendritic cells in the kidney. J Am Soc Nephrol 18:2628-2635

Kaissling B, Le Hir M (1994) Characterization and distribution of interstitial cell types in the renal cortex of rats. Kidney Int 45:709-720
Kaissling B, Spiess S, Rinne B, Le Hir M (1993) Effects of anemia on morphology of rat renal cortex. Am J Physiol 264:F608-617

Kaissling B, Hegyi I, Loffing J, Le Hir M (1996) Morphology of interstitial cells in the healthy kidney. Anat Embryol (Berl) 193:303-318

Kimura M, Asano M, Abe K, Miyazaki M, Suzuki T, Hishida A (2005) Role of atrophic changes in proximal tubular cells in the peritubular deposition of type IV collagen in a rat renal ablation model. Nephrol Dial Transplant 20:1559-1565

Kriz W, LeHir M (2005) Pathways to nephron loss starting from glomerular diseases-insights from animal models. Kidney Int 67:404-419

Kriz W, Hartmann I, Hosser H, Hahnel B, Kranzlin B, Provoost A, Gretz N (2001) Tracer studies in the rat demonstrate misdirected filtration and peritubular filtrate spreading in nephrons with segmental glomerulosclerosis. J Am Soc Nephrol 12:496-506

Kriz W, Hahnel B, Hosser H, Ostendorf T, Gaertner S, Kranzlin B, Gretz N, Shimizu F, Floege J (2003) Pathways to recovery and loss of nephrons in anti-Thy-1 nephritis. J Am Soc Nephrol 14:1904-1926

Kruger T, Benke D, Eitner F, Lang A, Wirtz M, Hamilton-Williams EE, Engel D, Giese B, Muller-Newen G, Floege J, Kurts C (2004) Identification and functional characterization of dendritic cells in the healthy murine kidney and in experimental glomerulonephritis. J Am Soc Nephrol 15:613-621

Kurtz A, Eckardt KU, Neumann R, Kaissling B, Le Hir M, Bauer C (1989) Site of erythropoietin formation. Contrib Nephrol 76:14 20 discussion 21-13

Kuusniemi AM, Lapatto R, Holmberg C, Karikoski R, Rapola J, Jalanko H (2005) Kidneys with heavy proteinuria show fibrosis, inflammation, and oxidative stress, but no tubular phenotypic change. Kidney Int 68:121-132

Le Hir M, Besse-Eschmann V (2003) A novel mechanism of nephron loss in a murine model of crescentic glomerulonephritis. Kidney Int 63:591-599

Le Hir M, Kaissling B (1993) Distribution and regulation of renal ecto5 '-nucleotidase: implications for physiological functions of adenosine. Am J Physiol 264:F377-F387

Le Hir M, Eckardt KU, Kaissling B (1989) Anemia induces 5'-nucleotidase in fibroblasts of cortical labyrinth of rat kidney. Ren Physiol Biochem 12:313-319

Le Hir M, Eckardt KU, Kaissling B, Koury ST, Kurtz A (1991) Structure-function correlations in erythropoietin formation and oxygen sensing in the kidney. Klin Wochenschr 69:567-575

Le Hir M, Hegyi I, Cueni-Loffing D, Loffing J, Kaissling B (2005) Characterization of renal interstitial fibroblast-specific protein 1/ S100A4-positive cells in healthy and inflamed rodent kidneys. Histochem Cell Biol 123:335-346

Lemley KV, Kriz W (1991) Anatomy of the renal interstitium. Kidney Int 39:370-381

Li J, Deane JA, Campanale NV, Bertram JF, Ricardo SD (2007) The contribution of bone marrow-derived cells to the development of renal interstitial fibrosis. Stem Cells 25:697-706

Linden J (2006) New insights into the regulation of inflammation by adenosine. J Clin Invest 116:1835-1837

Liu Y (2004) Epithelial to mesenchymal transition in renal fibrogenesis: pathologic significance, molecular mechanism, and therapeutic intervention. J Am Soc Nephrol 15:1-12

Loffing J, Loffing-Cueni D, Hegyi I, Kaplan MR, Hebert SC, Le Hir M, Kaissling B (1996) Thiazide treatment of rats provokes apoptosis in distal tubule cells. Kidney Int 50:1180-1190

Lullmann-Rauch R (1987) Lysosomal storage of sulfated glycosaminoglycans in renal interstitial cells of rats treated with tilorone. Cell Tissue Res 250:641-648

Marxer-Meier A, Hegyi I, Loffing J, Kaissling B (1998) Postnatal maturation of renal cortical peritubular fibroblasts in the rat. Anat Embryol (Berl) 197:143-153 
Maxwell P (2003) HIF-1: an oxygen response system with special relevance to the kidney. J Am Soc Nephrol 14:2712-2722

Maxwell PH, Osmond MK, Pugh CW, Heryet A, Nicholls LG, Tan CC, Doe BG, Ferguson DJ, Johnson MH, Ratcliffe PJ (1993) Identification of the renal erythropoietin-producing cells using transgenic mice. Kidney Int 44:1149-1162

Maxwell PH, Ferguson DJ, Osmond MK, Pugh CW, Heryet A, Doe BG, Johnson MH, Ratcliffe PJ (1994) Expression of a homologously recombined erythopoietin-SV40 T antigen fusion gene in mouse liver: evidence for erythropoietin production by Ito cells. Blood 84:1823-1830

Maxwell PH, Ferguson DJ, Nicholls LG, Johnson MH, Ratcliffe PJ (1997) The interstitial response to renal injury: fibroblast-like cells show phenotypic changes and have reduced potential for erythropoietin gene expression. Kidney Int 52:715-724

Mazzucchelli L (2002) Protein S100A4: too long overlooked by pathologists? Am J Pathol 160:7-13

Mc Dermott R, Ziylan U, Spehner D, Bausinger H, Lipsker D, Mommaas M, Cazenave JP, Raposo G, Goud B, de la Salle H, Salamero J, Hanau D (2002) Birbeck granules are subdomains of endosomal recycling compartment in human epidermal Langerhans cells, which form where Langerin accumulates. Mol Biol Cell 13:317-335

Meyer TW (2003) Tubular injury in glomerular disease. Kidney Int 63:774-787

Picard N, Baum O, Vogetseder A, Kaissling B, Le Hir M (2008) Origin of renal myofibroblasts in the model of unilateral ureter obstruction in the rat. Histochem Cell Biol

Plotkin MD, Goligorsky MS (2006) Mesenchymal cells from adult kidney support angiogenesis and differentiate into multiple interstitial cell types including erythropoietin-producing fibroblasts. Am J Physiol Renal Physiol 291:F902-F912

Pozdzik AA, Salmon IJ, Debelle FD, Decaestecker C, Van den Branden C, Verbeelen D, Deschodt-Lanckman MM, Vanherweghem JL, Nortier JL (2008) Aristolochic acid induces proximal tubule apoptosis and epithelial to mesenchymal transformation. Kidney Int 73:595-607

Quan TE, Cowper S, Wu SP, Bockenstedt LK, Bucala R (2004) Circulating fibrocytes: collagen-secreting cells of the peripheral blood. Int J Biochem Cell Biol 36:598-606

Remuzzi G, Bertani T (1998) Pathophysiology of progressive nephropathies. N Engl J Med 339:1448-1456

Rosenberger C, Griethe W, Gruber G, Wiesener M, Frei U, Bachmann S, Eckardt KU (2003) Cellular responses to hypoxia after renal segmental infarction. Kidney Int 64:874-886

Rosenberger C, Rosen S, Heyman SN (2005) Current understanding of HIF in renal disease. Kidney Blood Press Res 28:325-340

Rossini M, Cheunsuchon B, Donnert E, Ma LJ, Thomas JW, Neilson EG, Fogo AB (2005) Immunolocalization of fibroblast growth factor-1 (FGF-1), its receptor (FGFR-1), and fibroblast-specific protein-1 (FSP-1) in inflammatory renal disease. Kidney Int 68:2621-2628

Sakairi T, Hiromura K, Yamashita S, Takeuchi S, Tomioka M, Ideura H, Maeshima A, Kaneko Y, Kuroiwa T, Nangaku M, Takeuchi T, Nojima Y (2007) Nestin expression in the kidney with an obstructed ureter. Kidney Int 72:307-318

Sappino AP, Schurch W, Gabbiani G (1990) Differentiation repertoire of fibroblastic cells: expression of cytoskeletal proteins as marker of phenotypic modulations. Lab Invest 63:144-161

Schmid TC, Loffing J, Le Hir M, Kaissling B (1994) Distribution of ecto-5'-nucleotidase in the rat liver: effect of anaemia. Histochemistry 101:439-447

Soos TJ, Sims TN, Barisoni L, Lin K, Littman DR, Dustin ML, Nelson PJ (2006) CX3CR1+ interstitial dendritic cells form a contiguous network throughout the entire kidney. Kidney Int 70:591-596

Strutz F, Okada H, Lo CW, Danoff T, Carone RL, Tomaszewski JE, Neilson EG (1995) Identification and characterization of a fibroblast marker: FSP1. J Cell Biol 130:393-405

Sundelin B, Bohman SO (1990) Postnatal development of the interstitial tissue of the rat kidney. Anat Embryol (Berl) 182:307-317

Takahashi-Iwanaga H (1991) The three-dimensional cytoarchitecture of the interstitial tissue in the rat kidney. Cell Tissue Res 264:269-281

Thedieck C, Kalbacher H, Kuczyk M, Muller GA, Muller CA, Klein G (2007) Cadherin-9 is a novel cell surface marker for the heterogeneous pool of renal fibroblasts. PLoS ONE 2:e657

Theilig F, Bostanjoglo M, Pavenstadt H, Grupp C, Holland G, Slosarek I, Gressner AM, Russwurm M, Koesling D, Bachmann S (2001) Cellular distribution and function of soluble guanylyl cyclase in rat kidney and liver. J Am Soc Nephrol 12:2209-2220

Thompson LF, Ruedi JM, Glass A, Low MG, Lucas AH (1989) Antibodies to 5'-nucleotidase (CD73), a glycosyl-phosphatidylinositol-anchored protein, cause human peripheral blood $\mathrm{T}$ cells to proliferate. J Immunol 143:1815-1821

Vallon V (2003) Tubuloglomerular feedback and the control of glomerular filtration rate. News Physiol Sci 18:169-174

van Kooten C, Daha MR (2001) Cytokine cross-talk between tubular epithelial cells and interstitial immunocompetent cells. Curr Opin Nephrol Hypertens 10:55-59

Yang D, Zhang Y, Nguyen HG, Koupenova M, Chauhan AK, Makitalo M, Jones MR, St Hilaire C, Seldin DC, Toselli P, Lamperti E, Schreiber BM, Gavras H, Wagner DD, Ravid K (2006) The A2B adenosine receptor protects against inflammation and excessive vascular adhesion. J Clin Invest 116:1913-1923

Zeisberg M, Strutz F, Muller GA (2001) Renal fibrosis: an update. Curr Opin Nephrol Hypertens 10:315-320

Zhu MQ, De Broe ME, Nouwen EJ (1996) Vimentin expression and distal tubular damage in the rat kidney. Exp Nephrol 4:172-183 